\title{
Global Factors in the Term Structure of Interest Rates
}


Global Factors in the Term Structure of Interest Rates

Mirko Abbritti, Salvatore Dell'Erba, Antonio Moreno, and Sergio Sola 


\title{
IMF Working Paper
}

Fiscal Affairs Department

\section{Global Factors in the Term Structure of Interest Rates}

Prepared by Mirko Abbritti, Salvatore Dell'Erba, Antonio Moreno, and Sergio Sola ${ }^{1}$

Authorized for distribution by Abdelhak Senhadji

November 2013

\section{This Working Paper should not be reported as representing the views of the IMF.} The views expressed in this Working Paper are those of the author(s) and do not necessarily represent those of the IMF or IMF policy. Working Papers describe research in progress by the author(s) and are published to elicit comments and to further debate.

\begin{abstract}
This paper introduces global factors within a FAVAR framework in an empirical affine term structure model. We apply our method to a panel of international yield curves and show that global factors account for more than 80 percent of term premia in advanced economies. In particular they tend to explain long-term dynamics in yield curves, as opposed to domestic factors which are instead more relevant to short-run movements. We uncover the key role for global curvature in shaping term premia dynamics. We show that this novel factor precedes global economic and financial instability. In particular, it coincides with immediate expectations of permanent expansionary monetary policy during the recent crisis.
\end{abstract}

JEL Classification Numbers: C32, E43, F41, G12

Keywords: Yield Curve, Global Factors, FAVAR, Affine Term Structure Models, Term Premium

Author's E-Mail Address: mabbritti@unav.es; sdellerba@imf.org; antmoreno@unav.es; ssola@imf.org

\footnotetext{
${ }^{1}$ Most of the research in this paper was undertaken while Salvatore Dell'Erba and Sergio Sola were affiliated with the Graduate Institute of International and Development Studies.
} 


\section{Contents Page}

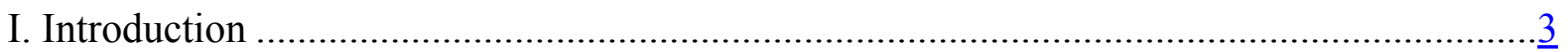

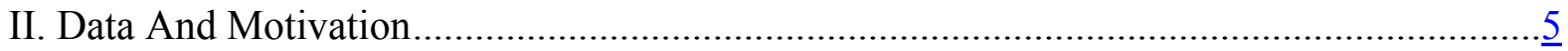

III. A Global Term Structure Model ………………….......................................................

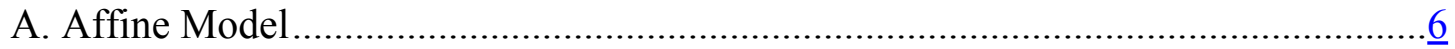

B. Effects of Global Shocks....................................................................................

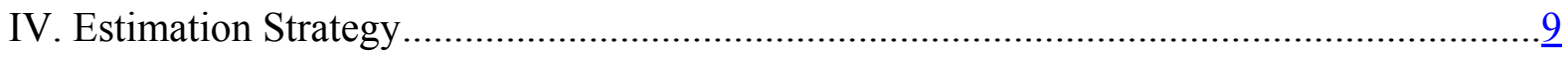

A. Estimation of the Latent Factors ……………………………………………...10

B. Estimation of the Remaining Parameters ..............................................................

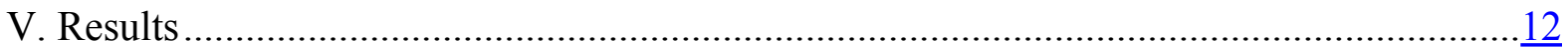

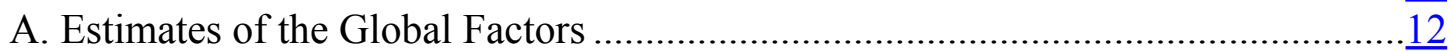

B. Model Performance _.................................................................................14

C. How Important are Global Factors for Domestic Factors and Yields? ....................14

D. Term Premia Dynamics ……………………………………………….....16

E. Global Factors and Term Premium Dynamics .......................................................

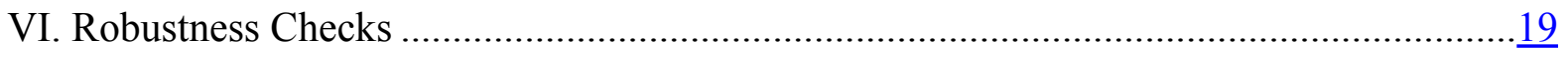

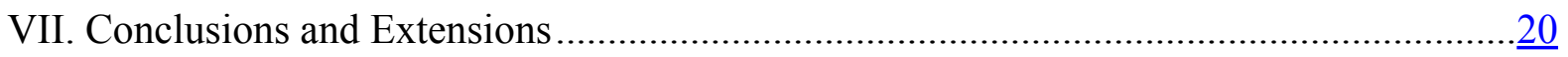

Tables

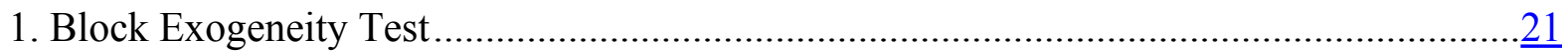

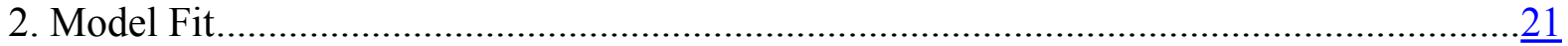

3. Variance Decomposition - Domestic Factors................................................................22

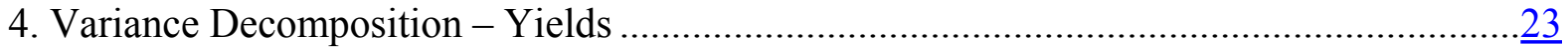

5. Variance Decomposition - Term Premia......................................................................

6. Variance Decomposition - Forward and Risk Neutral Rates ...........................................24

7. Variance Decomposition - Robustness to Bias Correction ………………………….......

8. Variance Decomposition - Term Premia - Subsample 1990Q1-2007Q2 …………............25

9. Variance Decomposition - Term Premia - Subsample 1990Q1-2007Q2 ……………........26

Figures

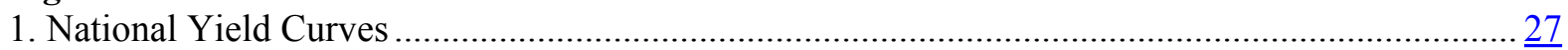

2. National Yield Curves - First Three Factors.......................................................................... $\frac{28}{28}$

3. First and Second Global Factors Dynamics ……………………………………………... $\frac{28}{28}$

4. Third Global Factor Dynamics..............................................................................................

5. Global Yield Curve (2007-08) ......................................................................................

6. Responses of Local Yield Factors to Global Factors in the UK.................................................. $\frac{31}{32}$

7. Contribution of Global Shocks to the Yield Curves Dynamics.......................................................

8. Term Premia Dynamics....................................................................................................

9. Historical Decomposition: Contribution of Local and Global Shocks to Term ............................... $\frac{34}{35}$

10. Impulse Responses of the Term Premia to Global Shocks......................................................... $\frac{35}{36}$

11. Contribution of Global Shocks to the Term Premium Dynamics - Japan ………………………... $\frac{36}{36}$

12. Contribution of Global Shocks to the Term Premium Dynamics - UK........................................... $\frac{37}{37}$

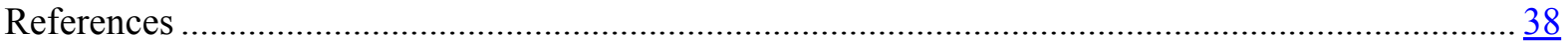




\section{INTRODUCTION}

Why are there shifts in yield curves across countries? What makes a long-term bond riskier than a short-term bond? What are the elements which determine the variation over time of the "price of risk"? These questions lie at the heart of many monetary policy discussions held by policy makers, academics and bond market participants. Time variation in term premia can in fact greatly complicate the task of central banks. Recent empirical studies have undertaken the difficult task of estimating term premia from the yield curves of bond markets and have reached considerable success. This development was made possible by a new class of models (so called no-arbitrage "affine" models) which, by replicating the dynamics of the entire yield curves can provide accurate measures of the time-varying risk premia on longterm bonds. As a result, researchers have used them to back out this risk component associated with the pricing of long-term bonds.

However, the effects of global forces on the dynamics of interest rates have been relatively less studied. Yet, there are compelling reasons to assert that global shocks impact crosscountry government yield curves. The recent credit crisis, for instance, shows that macrofinance shocks can be crucially transmitted internationally. As a consequence of financial integration, a sizable amount of domestic government debt is held by foreigners in global capital markets. Thus, positions on foreign bonds are naturally affected by home macrofinance conditions, and vice-versa. Despite these important stylized facts, studies on the term structure of interest rates tend to pay very little attention to international spillovers in yield curves. This paper takes up this challenge and investigates the role of global factors in the yield curves of several industrialized countries.

We introduce a role for global factors by modeling the law of motion for the yield curves as a factor augmented VAR (FAVAR) as in Stock and Watson (2005). In our model the traditional determinants of the yield curves - level, slope and curvature - are accompanied by a set of global factors, which we call - by analogy - "global level", "global slope" and "global curvature". Our sample covers the yield curves of seven open economies: Canada, United Kingdom, Japan, Germany, Australia, New Zealand and Switzerland.

We show that global factors are the ultimate drivers of both yield curve and term premia dynamics across countries. Moreover, our global factors have a clear economic interpretation. The level is global expected inflation and the slope mimics global growth. Importantly, we uncover a key role for global curvature, a factor completely ignored in the previous literature. We show that this factor is similar to a long-run risk factor, closely related to future financial and economic instability, triggering immediate expectations of expansionary monetary policy. A shock to global curvature substantially increases the term premium. We link this finding to monetary policy responses, especially following the recent credit crisis shock. As Central Banks engaged in unconventionally persistent expansionary policies in a time of global liquidity scarcity, expected short-rates plummeted with respect to long-rates, giving rise to an increase in the risk component of long-term bonds.

This study relates to the rapidly growing literature on affine term structure models. This recent and lively area of research first included macro factors explicitly with the work of Ang and Piazzesi (2003), and was later enriched by studies which provided a more structural 
interpretation of latent yield curves factors (see Rudebusch and Swanson 2008 and Bekaert, Cho and Moreno 2010 among others). Common features of these models are a set of restrictions which impose non-arbitrage conditions across all the different assets. In general, they follow a closed-economy framework and the vast majority of them is estimated using only U.S. Treasury yield curve data. Only very recently have some studies analyzed the implications of these models for a broader set of countries. Wright (2011) for instance, shows that affine term structure models have a remarkably good fit also when applied to countries other than the US. Moreover he also shows that the model implied term premia display strikingly similar patterns across industrialized countries. Similarly, Spencer and Liu (2010) exploit international information to explain term structure dynamics in U.K., U.S. and Switzerland.

The introduction of global factors in an affine term structure model is also justified by a large and growing body of literature which points towards the importance of common sources of fluctuations across interest rates in advanced economies. As predicted by economic theory, progressive financial and economic integration implies global asset pricing determination and, as a result, macroeconomic and financial factors tend to co-move in response to a relatively small number of global shocks (see Modugno et al, 2009, Hellerstein, 2011, and Dell'Erba and Sola, 2013). For instance, Bauer and Díez de los Ríos (2012) assume complete markets and full financial integration and estimate affine term structure models imposing the uncovered interest rate parity. As a result, in their setting only global factors matter and exchange rate changes and stochastic discount factor ratios track each other very closely. Our approach is similar to Jotikashtira Le and Lundblad (2012) in that we do not impose these international finance restrictions and both global and local/idiosyncratic factors can potentially matter. We select global factors that are shown to capture global macro-finance dynamics and study their impact across countries in the context of an affine term structure model.

Our work is closely related to Moench (2008) and Diebold, Li and Yue (2008). We borrow from Diebold, Li and Yue (2008) most of the building blocks necessary for a multi country affine term structure model, but we enrich the dynamics of the state variables by adopting a structure similar to the FAVAR presented by Moench (2008) to describe the U.S. term structure. Moench (2008) estimates an affine term structure model for the US where the interest rates are assumed to be a function of a large range of macroeconomic variables whose information is collapsed into a small number of unobserved latent factors. Diebold, Li and Yue (2008), instead, estimate a multi country affine term structure model with global and idiosyncratic factors. They show that two global factors - "global level and global slope" are largely responsible for the co-movements of the yield curves in industrialized economies.

This article differs from Diebold, Li and Yue (2008) in many important aspects. First, and more importantly, we show that together with global level and global slope, also a third factor - which we call global curvature - is important in explaining the dynamics of the interest rates. We show that this factor, which turns out to be especially important for explaining long run variations in interest rates and the term premium, is a forward indicator of financial and macroeconomic risk. Second, we complete their analysis by analyzing the dynamic propagation of global shocks on both the dynamics of the yield curves and the term premia in different countries. As stated by Bernanke (2006), monetary policy makers closely 
watch term premium dynamics with a view to stimulating or restraining liquidity in the economy. Third, following Bauer, Rudebush and $\mathrm{Wu}$ (2012, 2013), our model employs the inverse bootstrap bias correction in the estimation of the FAVAR. In their recent work, they have shown that the high persistence of the data in affine term structure models can severely worsen the small sample bias problem from which they are affected. ${ }^{2,3}$

This paper proceeds as follows. In Section II we present the data and some descriptive evidence in support of the presence of global factors. Section III describes the building blocks of our term structure model. Section IV explains the estimation methodology and Section V discusses our main results. Section VI briefly highlights some robustness checks that we conducted and Section VII concludes.

\section{Data And Motivation}

We use the dataset constructed in Wright (2011). The data comprises yields to maturity on zero coupon yield curves for seven countries: United Kingdom, Canada, Germany, Japan, Australia, New Zealand and Switzerland starting in 1990 and ending in the first quarter of $2009 .{ }^{4}$ We do not study the dynamics of the US yields or term premia, given that it is not a small open economy. However, as explained in the subsection on latent factor estimation, we make use of the US yield curve to construct the global factors affecting our set of countries. In this analysis we use quarterly frequency which we compute as simple averages of the monthly observations. Yields are available for maturities running from three months to ten years resulting in 40 series of zero coupon yields per country.

A first glance at the data helps us understand the importance of global factors in driving the co-movement of the yield curves across advanced economies. Figure 1 plots the dynamics of interest rates from short to long maturities over time for the set of countries in our sample. It shows that the cross-country term structures are strongly correlated. Across all maturities, the level of the yield curves displays a strong downward trend starting from the beginning of the nineties. While overall yield curves exhibit a positive slope, the actual degree of the slope varies from country to country.

According to the macro-finance literature, the yield curves can be spanned by a small set of latent factors called "level", "slope" and "curvature". If co-movement across yield curves is a dominant feature, we should be able to gauge it by looking at the behavior of these three factors in different countries. Following the existing literature, we estimate the level, slope and curvature by extracting the first three principal components from the cross-section of the

\footnotetext{
${ }^{2}$ There are also relevant methodological differences with respect to Diebold, Li and Yue (2008). For instance, they use a Nelson-Siegel framework, whereas we employ an affine-no arbitrage model. Additionally, we estimate the factors via principal components, while they obtain latent factors via Kalman filter estimation.

${ }^{3}$ The first and third aspects, among others, also differentiate our paper from Jotikashtira Le and Lundblad (2012).

${ }^{4}$ Differently from Wright (2011) we exclude Norway and Sweden as the data are not available starting from the same date.
} 
term structures in our sample. Figure 2 plots the three factors. The first factor indeed displays strong co-movement across countries. In all cases it has a strong downward trend and the correlation coefficient among these series ranges from 0.83 to 0.98 . As for the other two factors, they show more volatility but the correlation becomes stronger starting from 2000 onwards.

The strong comovements across the level, slope and curvature factors of the different countries point towards the existence of global forces which may have a strong influence on the shape and evolution of the yield curves in general, and term premia in particular. What are, and how important are these global forces? These are the questions we will address in the context of the global term structure model which we introduce in the next section.

\section{A Global Term Structure Model}

\section{A. Affine Model}

Our model is a simple extension of a discrete-time affine term structure model of the sort employed by Ang and Piazzesi (2003), Cochrane and Piazzesi (2008) and Wright (2011). Let $p_{i t}^{n}$ represent the price at time $t$ of an $n$-period zero coupon bond for country $i$, and let $y_{i t}^{n}=-\log \left(p_{i t}^{n}\right) / n$ denote its yields. If $m_{i t+1}$ denotes the nominal pricing kernel, bond prices can be recursively computed as:

$$
p_{i t}^{n}=E_{t}\left(m_{i t+1} p_{i t+1}^{n-1}\right) .
$$

We assume that the pricing kernel $m_{i t+1}$ is conditionally lognormal:

$$
m_{i t+1}=\exp \left(-r_{i t}-\frac{1}{2} \lambda_{i t}^{\prime} \lambda_{i t}-\lambda_{i t}^{\prime} \varepsilon_{i t+1}\right)
$$

where $\lambda_{i t}$ is the time varying price of risk and $\varepsilon_{i t+1}$ is an i.i.d. shock which is normally distributed $\varepsilon \sqcup \mathrm{N}(0, \mathrm{I}) .^{5}$ Following the existing literature, we assume the price of risk to be an "affine" (linear) function of a vector of $M$ latent state variables which we include in the vector $Y_{i t}$ :

$$
\lambda_{i t}=\lambda_{0}+\lambda_{1} Y_{i t}
$$

The state vector determines the reaction of the short-term rate of country $i, y_{i t}^{1}$, and even in this case this relationship is supposed to be linear:

$$
y_{i t}^{1}=\delta_{0}+\delta_{1}^{\prime} Y_{i t}
$$

${ }^{5}$ If $\lambda_{i t}=0$, the model generates the pure "expectational hypothesis". 
Hence, changes in the state variables affect the short-term interest rates and - through noarbitrage relationships - the entire yield curve. The specification of the state vector allows us to distinguish the "global" versus the "local" determinants of the yield curves. In fact, we assume that the state vector is composed of two distinct sets of elements, a country specific state vector $X_{i t}$ and a "global" state vector $F_{t}$ :

$$
Y_{i t}=\left(\begin{array}{c}
X_{i t} \\
F_{t}
\end{array}\right)
$$

The model is then completed by specifying the law of motion for the state variables. Alternatively to the existing literature, we assume the dynamics of the system are described by a Factor Augmented VAR (FAVAR) model. The "local" state variables $X_{i t}$ and the "global" ones $F_{t}$ evolve according to:

$$
\begin{gathered}
X_{i t}=\mu+\Lambda_{i} F_{t}+\Phi_{i} X_{i t-1}+v_{i t} \\
F_{t}=\Omega F_{t-1}+\eta_{t} .
\end{gathered}
$$

The implicit assumption behind this formulation is that there are a small number of global forces, $F_{t}$, that drive the comovements of country-specific states, $X_{i t}$. Notice that, as standard in the FAVAR literature, we assume that global factors affect domestic factors, but domestic factors do not affect global factors (see, for instance, Diebold et al, 2008). We believe that this assumption, a "small open economy" assumption, is reasonable for all our selected countries. In fact, our FAVAR nests the standard closed economy models, in which global factors do not affect domestic factors $\left(\Lambda_{i}=0\right)$, as in Wright (2011), as well as the case in which the evolution of $X_{i t}$ strictly follows that of the global factors $\left(\Phi_{i}=0\right)$. Standard likelihood ratio tests can be used to assess whether the set of global factors enters significantly into the evolution equation for the $X_{i t}$. From a methodological point of view, this is not very different from standard affine term structure models, where the state vector is required to follow a VAR(1) process. The FAVAR model, in fact, can be easily rewritten in a VAR(1) form as:

$$
Y_{i t}=\tilde{\mu}+\Gamma Y_{i t-1}+\Psi u_{t}
$$

where $u_{t}=\left(\begin{array}{l}v_{i t} \\ \eta_{t}\end{array}\right)$ and the matrices $\widetilde{\mu}, \Gamma$ and $\Psi$ are:

$$
\begin{gathered}
\tilde{\mu}=\left(\begin{array}{l}
\mu \\
0
\end{array}\right) \\
\Gamma=\left(\begin{array}{cc}
\Phi_{i} & \Lambda \Omega \\
0 & \Omega
\end{array}\right) \\
\Psi=\left(\begin{array}{ll}
I & \Lambda \\
0 & I
\end{array}\right) .
\end{gathered}
$$


Since the short term rate is linearly related to the state vector, bond prices are exponential linear functions of the state vector:

$$
p_{i t}^{n}=\exp \left(A_{n}+B_{n}^{\prime} Y_{i t}\right)
$$

The scalar $A_{n}$ and the $m \times 1$ matrix of coefficients $B_{n}$ depend on time to maturity. Provided that no-arbitrage across maturities is guaranteed, the coefficients can be computed using the following recursive equations:

$$
\begin{gathered}
A_{n+1}=-\delta_{0}+A_{n}+B_{n}^{\prime}\left(\tilde{\mu}-\Psi \lambda_{0}\right)+\frac{1}{2} B_{n}^{\prime} \Psi \Psi^{\prime} B_{n} \\
B_{n+1}=\left(\Gamma-\Psi \lambda_{1}\right)^{\prime} B_{n}-\delta_{1} .
\end{gathered}
$$

The recursion starts with $A_{1}=-\delta_{0}$ and $B_{1}=-\delta_{1}$. Hence, for an $n$-quarters to maturity zero coupon bond the yield will be given by:

$$
y_{i t}^{n}=-\log \left(p_{i t}^{n}\right) / n=a_{n}+b_{n}^{\prime} Y_{i t}
$$

with $a_{n}=-\frac{A_{n}}{n}$ and $b_{n}^{\prime}=-\frac{B_{n}^{\prime}}{n}$.

Therefore, once we estimate the parameters of the FAVAR and the remaining model parameters, we will be able to generate yields at any given maturity, together with a series of forward rates. Using the generated yields we can compute term premia for all the countries in the sample.

\section{B. Effects of Global Shocks}

The dynamic structure of the FAVAR model allows us to analyze the propagation and the relative importance of global and local shocks in the dynamics of the yield curves. Hence in this section we show how to impose a structural identification and derive impulse responses to global and local shocks. Let us write out the FAVAR model in matrix form as:

$$
\underbrace{\left[\begin{array}{cc}
I & -\Lambda_{i} \\
0 & I
\end{array}\right]}_{\Xi} \underbrace{\left[\begin{array}{c}
X_{i t} \\
F_{t}
\end{array}\right]}_{Y_{t}}=\underbrace{\left[\begin{array}{cc}
\Phi_{i} & 0 \\
0 & \Omega
\end{array}\right]}_{\Upsilon} \underbrace{\left[\begin{array}{c}
X_{i t-1} \\
F_{t-1}
\end{array}\right]}_{Y_{t-1}}+\underbrace{\left[\begin{array}{c}
v_{i t} \\
\eta_{t}
\end{array}\right]}_{\omega_{i t}} .
$$

Given that the shocks to the local and global factor equations are uncorrelated, $E\left(v_{i t} \eta_{t}\right)=0$, the variance-covariance matrix of the errors is given by: 


$$
E\left(\omega_{i t} \omega_{i t}^{\prime}\right)=\left[\begin{array}{cc}
\Sigma_{v} & 0 \\
0 & \Sigma_{\eta}
\end{array}\right] .
$$

Suppose that we can find matrices $B_{0}$ and $C_{0}$ such that $B_{0} B_{0}^{\prime}=\Sigma_{\nu}$ and $C_{0} C_{0}^{\prime}=\Sigma_{\eta}$, with those matrices having structural identification restrictions, then it is true that:

$$
\underbrace{\left[\begin{array}{cc}
B_{0} & 0 \\
0 & C_{0}
\end{array}\right]}_{\Sigma}\left[\begin{array}{cc}
B_{0} & 0 \\
0 & C_{0}
\end{array}\right]^{\prime}=\left[\begin{array}{cc}
\Sigma_{v} & 0 \\
0 & \Sigma_{\eta}
\end{array}\right] .
$$

The impulse responses to these identified structural shocks are therefore obtained by simply inverting the FAVAR:

$$
Y_{t}=\left[I-\Xi^{-1} \Upsilon(L)\right]^{-1} \Xi^{-1} \tilde{\Sigma} .
$$

Alternatively, a more operational expression for the impulse response functions can be obtained by rewriting the equations of the FAVAR in terms of the lag operator:

$$
\begin{gathered}
X_{i t}=\Lambda_{i} F_{t}+\Phi_{i}(L) X_{i t}+v_{i t} \\
F_{t}=\Omega(L) F_{t}+\eta_{t} .
\end{gathered}
$$

We can invert the expressions above to obtain:

$$
\begin{gathered}
X_{i t}=\left[I-\Phi_{i}(L)\right]^{-1} \Lambda_{i} F_{t}+\left[I-\Phi_{i}(L)\right]^{-1} v_{i t} \\
F_{t}=[I-\Omega(L)]^{-1} \eta_{t} .
\end{gathered}
$$

These expressions imply that the response of the local factors $X_{i t}$ to "local shocks" can be computed from the moving average representation:

$$
X_{i t}=\left[I-\Phi_{i}(L)\right]^{-1} C_{0} \varepsilon_{i t}
$$

were $\varepsilon_{i t}$ is a vector of structural "local shocks". Similarly, the impulse responses of the local factors to " global shocks" can be computed from the moving average representation:

$$
X_{i t}=\left[I-\Phi_{i}(L)\right]^{-1}\left\{\Lambda_{i}[I-\Omega(L)]^{-1} B_{0} u_{i t}\right\}
$$

with $u_{i t}$ representing a vector of structural "global shocks".

\section{ESTIMATION STRATEGY}

The estimation of the model is undertaken in several steps (as in Joslin, Singleton and Zhu 2011, and Wright, 2011). The first step consists of estimating the two sets of global and local 
latent factors $F_{t}$ and $X_{i t}$. The second step is then to estimate the parameters of the FAVAR in (2), which can be obtained conditionally on estimates of the latent factors. The third step is to estimate the sets of parameters $\delta_{0}$ and $\delta_{1}$. Finally with a last step we can back out estimates for the last set of parameters, $\lambda_{0}$ and $\lambda_{1}$.

\section{A. Estimation of the Latent Factors}

The literature on affine term structure model often uses principal component analysis to find estimates of the state variables. Following Joslin, Priebsch and Singleton (2012), among others, we therefore define the set of domestic factors $X_{i t}$ as a vector containing the first three principal components extracted from the set of zero-coupon yields of maturities from three months to ten years in country $i$. Because of their shape, these factors are generally called: level, slope and curvature respectively. Abiding by this convention, we will name the elements of $X_{i t}$ "local level", "local slope"and "local curvature".

The global factors, on the other hand, should be able to capture "global forces" that drive the co-movement or cross-correlation of the yields in different countries. As hypothesized in the literature on "factor models" (Geweke, 1977, Stock and Watson, 2005, Bernanke, Boivin Eliasz, 2005 among others) we can in fact think that yields across different countries are a function of a small number of global factors. Hence, $F_{t}$ can be consistently estimated by extracting principal components from a matrix $M_{t}$ which includes the term structures of all the $N$ countries included in our sample, including the U.S.:

$$
M_{t}=\left\{y_{1 t}^{1}, \ldots, y_{1 t}^{n}, \ldots, y_{N t}^{1} \ldots, y_{N t}^{n}\right\} .
$$

From a methodological point of view, extracting latent factors from a set of variables taken from the different countries allows us to interpret the common factors $F_{t}$ as "global". In particular the elements in $F_{t}$ will be combinations of yields of different countries at different maturities which explain the highest proportion of correlation among interest rates in all countries over all maturities.

\section{B. Estimation of the Remaining Parameters}

Following Bernanke et al. (2005), after estimating the global and the local factors $F_{t}$ and $X_{i t}$ via principal components, we treat them as observable variables and estimate the parameters of the FAVAR $(\Gamma, \Psi$ and $\tilde{\mu})$ via standard OLS. Similarly, conditional on consistent estimates of the factors, we also obtain consistent estimates of the parameters $\delta_{0}$ and $\delta_{1}$ with a simple OLS regression of the short-term rate on $Y_{t}$.

Finally, the remaining parameters $\lambda_{0 i}$ and $\lambda_{1 i}$ which determine the evolution of the price of risk, are estimated, for instance, as in Cochrane and Piazzesi (2008) by minimizing for each country $i$ the sum of squared differences between actual and fitted yields: 


$$
\left\{\hat{\lambda}_{0 i}, \hat{\lambda}_{1 i}\right\}=\arg \min _{\lambda_{0 i}, \lambda_{1 i}} \sum_{t} \sum_{n}\left(y_{i t}^{n}-\tilde{y}_{i t}^{n}\right)^{2}
$$

where $\tilde{y}_{i t}^{n}=-\left(A_{n}+B_{n}^{\prime} Y_{t}\right) / n$ are the model implied yields of country $i$.

After having estimated these parameters, the model is able to generate the entire structure of the yields. It is therefore possible to compute the term premium associated with longer maturities. We compute the term premium as the difference between the model implied 5year forward rate 5 years from now and the average expected one-year rate 5 to 10 years from now.

Before passing on to the results of the paper, it is worth mentioning two methodological issues. The first issue refers to the possibility that some factors may be "unspanned". Several recent papers (see e.g. Duffee, 2008, Ludvigson and Ng, 2009, Bauer and De los Ríos, 2012, Joslin, Priebsch and Singleton, 2012, among others) have considered the possibility that some factors in a term structure model can be important for forecasting future interest rates, but may not be needed to fit the cross-section of current bond yields. This implies imposing zero restrictions in the short-rate responses to factors $\left(\delta_{i}\right)$ as well as on the vectors of prices of risk $\left(\lambda_{i}\right){ }^{6}$ In this paper we follow Wright (2011) and we treat the first three countryspecific factors $X_{i t}$ as "spanned", while the global factors $F_{t}$ are treated as unspanned. Under this assumption, global factors do not enter directly in the cross-section determination of interest rates, where only local factors appear. Global factors however can still affect the term structure through two main channels. On the one hand, they have an indirect contemporaneous effect on the yield curve through their spillover effect on the domestic factors. On the other hand, they help to forecast future yields.

The second issue refers to the possibility that the estimated state process dynamics may be distorted by small sample bias. As recently shown by Bauer, Rudebusch, and Wu (2012, 2013), the persistence in estimated term structure models can determine severe downward biases due to small sample problems. This problem is likely to translate into an unrealistically low degree of volatility in long-run short-rate expectations due to fast mean reversion, which distort estimates of long maturity term premia. To address this issue, we use the indirect inference bias correction methodology laid out in Bauer, Rudebush and Wu (2012) to correct for the small sample bias. ${ }^{7}$

\footnotetext{
${ }^{6}$ Technically this is obtained by imposing restrictions on the Q-measure representation of the state vector.

${ }^{7}$ As in Bauer, Rudebush and $\mathrm{Wu}$ (2012), we impose the restriction that bias-corrected estimates are stationary using the stationarity adjustment suggested in Kilian (1998). Using a standard bootstrap bias correction instead of the indirect inference bias correction does not affect our results.
} 


\section{Results}

In this section we report the empirical results obtained for our FAVAR term structure model. First we show the three estimated global factors and provide an intuitive macroeconomic explanation for each of them. We then assess the specification of our FAVAR model and evaluate its fit in terms of how well it can replicate yield curves across different maturities for different countries. Finally, we investigate the dynamics of the term premia and quantify the relative importance of global versus domestic factors in explaining their behavior.

\section{A. Estimates of the Global Factors}

In the first step of the estimation procedure, we extract common factors from the large panel of international yields using the principal components approach of Stock and Watson (2002). Since the first three principal components together account for more than 96 percent of the total variance of all yields, we consider three global factors in the analysis, which are depicted in Figures 3 and 4.

As with any estimation methodology based on principal components, the main issue with latent factors is that they miss an economic interpretation. The existing literature on affine term structure models has shown that level and slope factors in a country's yield curves are generally related to expected inflation and real activity. Following the closed-economy models we check whether global level and global slope have an "international" analogous interpretation. Indeed our results highlight that the behavior of the "global level" factor closely resembles a "global expected inflation factor" (Figure 3) which we compute as the first principal component extracted from a matrix containing one year ahead CPI inflation forecasts of the countries in our sample. ${ }^{8}$ The two series look remarkably similar and present a correlation of 0.94 .

Similarly we construct a "global real activity indicator" as the first principal component extracted from a matrix containing real GDP growth, industrial production and unemployment figures for the countries in our sample. The correlation between this index and the second global factor is 0.77 . The global real activity factor manages to capture the three downward movements experienced by the global slope factor between 1990 and 1995, then between 2000 and 2005 and finally during the Great Recession. For this last period however, the global real activity factor drops by less.

Finding an economic interpretation of the third global factor, a proxy for global curvature, is a novel task. Campbell et al. (2013) have recently proposed a theoretical link between curvature and the level of the term premia. They show in an asset-pricing model that term premia are driven by the the covariance between the real interest rate and inflation. They further show that this covariance has declined over time, driving down term-premia. Our empirical analysis in section V.D below shows term premia displaying a downward trend in a number of countries, but also experiencing high volatility and clear countercyclical

\footnotetext{
${ }^{8}$ Data are taken from the Consensus Economic Forecasts and are quarterly averages of monthly figures.
} 
dynamics, especially around the time of the recent credit crisis. We now go on to show that the dynamics of the third global factor precede a number of key macro-finance series.

Figure 4 plots the third global factor against a set of macro-finance indicators. The top two graphs show that the third global factor signals future macroeconomic stress. Macro risk, measured on the top left graph by the U.S. recession probabilities series constructed by Chauvet and Piger, closely follows the spikes of the global curvature factor at the beginning and at the end of the sample. Consistent with this finding, the top right panel shows that the standard deviation of the one-year ahead forecasts of US GDP growth starts to rise in the last crisis after the third global factor begins to peak. Thus, global curvature emerges as an indicator of future economic instability.

The middle left graph shows that the financial stress index published by the St. Louis Fed captures remarkably well the inversions in the tendency of the global curvature factor both in 2003 and at the onset of the recent crisis. The middle right graph of Figure 4 shows the third global factor together with the U.S. index of economic policy uncertainty developed by Baker et al.(2013). The graph shows that our third global factor leads the policy uncertainty index in the recent crisis. Baker et al. (2013) state that the policy uncertainty index has risen in this crisis due to fiscal and regulatory policy uncertainty but not due to monetary policy uncertainty. This is consistent with the view that monetary policy credibility was globally very high, a point which we explore below.

The bottom left graph compares global curvature with uncertainty over inflation. This is measured as the two-sided smoothed series of uncertainty of inflation (proxied by the standard deviation of one year ahead inflation forecasts based on US consensus data). We can see that in two cases (1990-1991 and 2007-2008), spikes in the third factor anticipates spikes in uncertainty over inflation, and that the two series show a high degree of correlation up until the early 2000 s recession $(77 \%)$ and moderate correlation in the overall sample $(64 \%)$.

While we observe a close link between the third factor and inflation uncertainty, it is interesting to further investigate this relation during the recent credit crisis (2007-2009). In particular, the recent crisis has been a severe demand crisis, coupled with a very expansionary monetary policy reaction. So, what does an increased inflation uncertainty mean: more or less inflation? To answer this question, the bottom right panel plots the third factor against the third moment of expected inflation in the US (the data we found available, which can capture similar dynamics to other countries). It shows that the distribution of inflation is clearly left skewed during the recent crisis, and thus most agents had deflation uncertainty during this time. This evidence is consistent with the findings of Fleckenstein et al. (2013) who show that markets price very similarly deflation risk and other types of tail risk like systemic financial risk.

The behaviour of the yield curve during the recent finantial crisis is consistent with an interpretation of global curvature as medium/long term macro and financial risk, that triggers expectations of expansionary monetary policy. In fact, the peak of our third factor in the third quarter of 2007 precedes the cross-country expansionary monetary policies engineered by policy makers in response to the global liquidity crunch. By 2009, monetary policy interest rates were very low in many of these countries, in some of them close to zero. But under 
credible monetary policy, expectations of lower term interest rates should have already reacted by the end of 2007. This is exactly what we observe in Figure 5, which plots the equally weighted average of the yield curves across the countries in our dataset. In the second quarter of 2007 the global yield curve was essentially flat at 4.5 percent. However, by the third and fourth quarter, it cleary becomes convex, with a marked hump-shape, as interest rates at intermediate maturities edge clearly lower. This reflects expectations of lower monetary policy rates. Clearly, monetary authorities did not lower interest rates immediately. It took some quarters. The right panel indeed shows that by the fourth quarter of 2008 the short-end of the yield curve was already at around 2 percent due to the global expansionary monetary policies.

Overall, this evidence suggests that the global curvature signaled medium/long-term risk during the last crisis, preceding severe macroeconomic downturns or disruptions in the financial markets. This is why we dub the third global factor as a long-term risk factor. Importantly, we have shown that monetary policy expectations immediately reflected this risk with a notable reduction of interest rates at middle maturities.

\section{B. Model Performance}

While there are many sound economic arguments to support the idea that global factors influence domestic term structures, it needs to be demonstrated that these effects are strong and statistically significant. One of the advantages of the FAVAR model (2) is that, by nesting the case in which global factors do not affect domestic factors $\left(\Lambda_{i}=0\right)$, it allows us to formally test the importance of global factors for the dynamics of the local level, slope and curvature factors.

Table 1 shows the results of the likelihood ratio tests where we test formally whether the coefficients of the matrix $\Lambda_{i}$ in the FAVAR are jointly statistically different from zero. Under the null hypothesis, the dynamics of domestic factors are independent from global factors. The degrees of freedom are corrected as in Sims (1980) for the number of parameters in each equation. For all the countries considered, the block exogeneity test very strongly rejects the null of no-effects of the global factors. We interpret these results as a validation of our empirical model and as an important starting point in uncovering the relationship between global forces and yield curve dynamics.

To evaluate the fit of the model, Table 2 shows the root mean square fitting error of yields, i.e. the square root of the minimum value of the objective function in equation (4). The fit of the model is excellent. The typical fitting errors range between 1.5 and 6 basis points, with New Zealand, Germany and Japan exhibiting the best fit.

\section{How Important are Global Factors for Domestic Factors and Yields?}

In our model, we have implicitly assumed a hierarchical structure, in which country yields depend only on country-specific factors, but these are in turn affected by the dynamics of global forces. Any influence of global factors on domestic interest rates can thus come only through their effect on the domestic level, slope and curvature factor. To understand the 
effect of global forces on country yields, in this section we use the FAVAR model to perform two exercises. We first analyze the impulse responses of domestic factors to global shocks. We then compute the variance decomposition exercise of the three local factors included in the vector $X_{i t}$.

To perform these exercises, global shocks are identified with a simple Choleski decomposition. Using the macroeconomic interpretation of the global factors, we order the second global factor, capturing global real activity (slope), as first, the global long-run risk (curvature) factor as second, and the global expected inflation (level) factor last. It is important to bear in mind that, because the factors are extracted through principal components, they are orthogonal to each other and therefore their relative ordering within a VAR does not matter for the results.

Figure 6 shows the dynamic response of local yield factors to global forces in the case of the UK. ${ }^{9}$ The unreported results for other countries give a similar picture. ${ }^{10}$ Global forces are found to have a sizeable and persistent effect on domestic factors. A positive innovation to the global slope factor is found to have a positive effect on both the domestic level and slope factor, consistent with the idea that a global boom tends to induce both an improvement in the domestic cycle and an increase in the domestic inflation risk. Notice that both effects are delayed and very persistent. An increase in the global curvature factor instead is related to an increase in the domestic curvature and a reduction in the domestic level and slope factors. These last two effects can be caused by the aggressive expansionary monetary policy following the last global curvature shock, which was likely perceived as a long-run risk crisis shock in the recent credit crisis. The drop in slope is caused by a larger drop in the long-rate, due to the expected persistent lowering of the short-rate. Notice that the effect of this shock is small on impact but more persistent, as it remains significantly different from zero for more than 30 quarters. Finally, a shock to global level loads positively on the country's yield curve level factor (i.e. the country's inflation risk factor), while the effect on local slope and curvature is small, and, more generally, may differ from country to country.

Table 3 shows the contribution of global shocks to the variance of the local factors at two forecasting horizons: 1 quarter and 40 quarters. At short horizons, country specific shocks explain most of the variance of the three local factors, but global factors are far from unimportant. Global factors explain, on average, 54 percent of the local level, 24 percent of the local curvature but only 3 percent of the local slope. The importance of global factors rapidly increase with the horizon. For most of the countries the level of interest rates is explained - at a 10 year-horizon - almost entirely by the global factors. The proportion of explained variance for the level factor in fact ranges between 95.5 percent in Japan and 99.3 in Germany. Global factors also explain more than 50 percent of the variance of the domestic slope and curvature.

\footnotetext{
${ }^{9}$ Confidence intervals are obtained using the bootstrap-after-bootstrap method as described in Kilian (1998).

${ }^{10}$ All results are available upon request from the authors.
} 
Since global factors are important determinants of local factors, we expect them to have sizeable effects on domestic yield curves. Figure 7 shows the contribution of global shocks for the variance of domestic yields across maturity (first graph) and forecasting horizon (second graph). At a 40-quarter horizon, global shocks explain more than 80 percent of the variance of yields, across all maturities. This effect is found to increase with the maturity, and to reach a maximum between 15 and 25 quarters, depending on the country. Regarding the effect of the forecasting horizon considered, we find that on impact $(\mathrm{h}=1$ quarter) domestic shocks explain, in most countries, most of the variance of the yields. Already after 4 quarters, however, global shocks dominate the variance decomposition of domestic yields, confirming the idea that the effect of global shocks tends to be large but delayed.

Table 4 decomposes the contribution of global forces to long and short rates into the portions due to each of the three global factors. The global long-run risk and the global real activity factor are found to explain, on average, more than 35 percent of the 3 month rate, while the global expected inflation factor only accounts for 12 percent of the forecasting variance of the short rate. At longer maturities, the importance of the expected inflation factor increases, while the relevance of the other two factors is slightly reduced.

Overall, these results point towards a crucial importance of global factors in explaining domestic yields curves. Diebold et al. (2008) showed the importance of two global yield factors related to global inflation and economic activity. Our results suggest that a third global factor needs also to be taken into account, a long-run risk factor related to future economic/financial instability. We now show that this factor is also key in explaining term premium dynamics.

\section{Term Premia Dynamics}

One of the interesting properties of the affine term structure models is that they allow researchers to decompose long rates into the risk neutral rate and term premia. Term premia are the excess returns that investors ask to be indifferent between holding a short and a longterm instrument. In presence of risk aversion, in fact, investors need to be compensated for the risk of holding a long-term instrument with a return that is above the simple average of expected short term rates. In our default-free setting, term premia could reflect nominal and real risks, such as inflation (Gurkaynak, Sack and Swanson (2005)) and unemployment (GilAlana and Moreno (2012)), or potentially other macroeconomic and financial risks.

We therefore use our FAVAR model to estimate time varying term premia. Following Wright (2011) we compute them as the difference between the model-implied 5-to-5 year forward rate and the average expected one-year rates 5-to-10 year hence. Figure 8 shows the implied term premium of our FAVAR term structure across countries. To ease visualization, we divide the countries in two groups: the Pacific countries - Japan, Australia and New Zealand - and the Western countries - UK, Germany, Switzerland and Canada.

In all countries, the term premium has declined from the beginning of the nineties until the early 2000s, but has started to increase afterwards, first quite smoothly, and then rapidly at the onset of the recent crisis. The Great Recession has been associated, in most countries, with an increase of the term premium of about 4 percentage points. Interestingly, the 
dynamics of term premia in Western economies is consistently more volatile than in the Pacific countries.

Notice that the dynamics of the term premia implied by the FAVAR term structure model are more volatile and countercyclical than the dynamics in Wright (2011) and Bauer, Rudebusch and $\mathrm{Wu}$ (2013). The higher volatility with respect to Wright (2011) was expected, because we correct the FAVAR estimates for the small-sample bias, which tend to make the estimated system less persistent. The higher volatility with respect to Bauer, Rudebusch and $\mathrm{Wu}$ (2013), instead, suggests that the presence of global factors further increases the volatility of the expectations of future short-term interest rates, especially at longer horizons. Notice also that the term premium can become negative for some countries, especially after the mid-1990s. As Campbell et al (2013) have shown, this situation can arise under a negative correlation between stock market and bond market returns. In this instance, longterm bonds can hedge against stock market losses and, in general, against the backdrop of recession times. As a result, investors are eager to accept lower returns on long-term bonds vis à vis short-term bonds.

In general, the dynamics of the term premia have been associated to the so called "inflation risk". The declining pattern in the early part in Figure 8 would therefore be evidence that central banks, with the adoption of an explicit target for inflation have managed to anchor inflationary expectations and therefore reduced term premia. The increase observed in the last part of the sample, however, suggests that there might be something more to it. Thus, it is important to ask whether these term premia dynamics are due to developments in the domestic economies or to global developments, because the implications for policy-makers may be strikingly different. This is a task that we perform in the following section.

\section{E. Global Factors and Term Premium Dynamics}

To get a first impression of the importance of global forces for term premia dynamics, Figure 9 shows the counterfactual term premia that would arise if countries were hit only by local or global shocks, respectively. Specifically, in this exercise we shut down all domestic (global) shocks to derive, conditional on the estimated parameters, counterfactual term premia due completely to global (local) shocks.

Term premia dynamics appear to be mainly determined by global factors. In particular, the patterns of term premia generated with only global factors, reflect both the steady decline of the first part of the sample and the steep increase associated with the Great Recession, and always move closely to actual term premia. When we include only local shocks, instead, the generated series sometimes depart significantly from the actual term premium, indicating that local shocks are less important in explaining their dynamics. The reason is that global factors explain most of the variance of local factors at longer horizons.

Table 5 reports the variance decompositions in term premia dynamics. The contribution of global factors to term premia variations ranges between 65 percent in the case of Germany to 92 percent in the case of the UK. The global curvature factor is, on average, the most important in explaining term premia variation, as it explains around 60 percent of the total 
variance at the 40 quarters horizon. This happens mainly because shocks to global curvature explain most of the variance of the risk neutral rate, which indicates that the third global factor has a large forecasting power for future short-term yields. This confirms the results in Dahlquist and Hasseltoft (2012), who also find that global shocks have an important effect on future expected short-term rates. We further refine their result and show that the global curvature shock is instrumental in this respect. Indeed, following a global curvature shock, perceived as a long-run risk shock in the recent credit crisis, the monetary policy authority aggressively and persistently lowered short-rates, thus lowering the risk neutral rate. The global level factor is instead the most important in explaining forward rates dynamics (see Table 6).

To get further intuition on the effect of global factors on term premia dynamics, Figure 10 shows the impulse responses of the term premium to each of the three global shocks. A positive shock to the global real activity factor induces in most countries a reduction in the term premium. This is consistent with the idea that uncertainty related to macroeconomic downturns drives investors away from long-term assets (see Abbritti et al. 2012) and might therefore be an important factor behind the recent spikes in term premia. The only exceptions are Australia and New Zealand, where the transmission mechanism is positive, but small.

An increase in the global curvature factor, instead, produces an increase in term premia across countries. This effect is relatively large, especially in Western countries, and very persistent, as it usually lasts more than 30 quarters. Since the risk-neutral rate decreases more than the long (forward) rate -due to the credible monetary policy action-, the term premium increases significantly. Interestingly, Campbell et al (2013) have recently highlighted the importance of the yield curve curvature in shaping bond term premia. In particular, they show that the intermediate part of the term structure can react more than the long-end following macro shocks. In their model, this happens because the intermediate part of the yield curve reacts both to permanent and transitory shocks, whereas the long end only reacts to the permanent part. In our model the global yield curve becomes more convex following a curvature shock -see Figure 5 in the context of the recent credit crisis- and as a result term premium across countries increases. Thus our results provide empirical support for the relevance of the curvature factor on term premium dynamics, extending it to an international context.

An increase in global level -related to inflation- induces an increase in the term premium in all countries except Germany. In Germany, the term premium actually decreases following a shock to the global expected inflation factor because, even though long rates and the forward rate increase after the shock, the risk neutral rates increase by more. This can be explained by the high credibility of its monetary policy stance.

Figures 11 and 12 show the contribution of global shocks to term premia dynamics in the case of Japan and the UK. In the case of Japan the dynamics of the term premium are very similar to the ones that would have arisen if the global level shock were the only shock in the system. This is not surprising, given that Japan is the only country in our sample in which the global expected inflation factor explains most of the variance. The global curvature and the global slope factors help to explain the increase in the term premium during the recent crisis. In the case of the UK, term premium dynamics are mostly explained by the global long-run 
risk factor, while the global inflation factor is mainly responsible for the decrease of the term premium in the first part of the sample.

Overall, one can detect a consistent pattern across countries. The global expected inflation factor is the main responsible for the downward trend of term premia in most countries, especially in the first part of the sample. The global real activity factor and, especially, the global long-run risk factor appear instead the main determinants of the short run fluctuations around this trend and, more importantly, of the large increase in term premia at the onset of the Great Recession.

\section{RobUSTNeSS CHeCKS}

We test the robustness of our results with three main exercises. First, to understand to what extent bias correction affects our conclusions, we compare the main results reported above (under bias correction) with analogs obtained without bias correction. As in Bauer, Rudebusch and Wu (2012 and 2013), we find that bias correction has important effects on the identification of the term premium. For all countries, the term premium identified with simple OLS presents a clearer downward sloping trend; it is less volatile/countercyclical and does not increase as much as in the Great Recession. The conclusions about the importance of global factors, however, hold independently of the bias correction in the state process (Table 7). Bias correction slightly increases the total contribution of global shocks, but in the model estimated with simple OLS, global shocks still account, on average, for more than 70 percent of the total variance in the term premia. However, bias correction affects the relative contribution of the three shocks. Under OLS, the contribution to the total variance attributed to the global expected inflation shock almost doubles, from 16 to 29 percent, while the contribution of the third global factor is reduced. These results are coherent with the conclusions by Bauer, Rudebusch and Wu (2012 and 2013) and Abbritti, Alana, Lovcha and Moreno (2012), who show that, taking the term structure persistence correctly into account reduces the importance of expected inflation for term premia dynamics, while it increases the importance of real shocks.

In the second exercise, in order to assess the impact of the Great Recession on the estimation, we re-estimate the model for the 1990Q1-2007Q2 period, i.e. we leave out the last eight observations of our original sample. The average contribution of global factors to term premia dynamics is only slightly reduced, from 85 to 77 percent. In the shorter sample, the relative importance of expected inflation increase, explaining on average 47 percent of the variance of the term premia, while the third global factor only accounts for 13 percent of the total variance (Table 8). This confirms the idea that the reduction of inflation risk has been the main driver of the reduction of term premia until the early 2000s, while the events related to the Great Recession are captured, in our model, by the third global factor.

In the third exercise, we treat the US factors as the global ones. This is justified by the relevance of the US in the global economy as well as the importance of US monetary policy on global financial markets (see, for instance, Jotikashtira et al, 2012). In Table 9 we show the variance decomposition of the term premia across countries. We find that global factors

are still key to explain term premia variations (above $80 \%$ ) and that global curvature is the 
most important factor. Nevertheless, with respect to the baseline model, it loses explanatory power in favor of the global cycle factor.

\section{Conclusions AND EXTENSIONS}

Recent term structure models have emphasized restrictions implied by no-arbitrage conditions in the market for government bonds of different maturities. In contrast, they have for the most part overlooked the implications of international financial linkages embedded in global financial markets free of restrictions to capital mobility. In this paper, we postulate a general framework to account for systematic international linkages among term structures while retaining the more traditional no-arbitrage structure.

Our results show that global factors explain an important share of fluctuations in the term premia of a panel of small-open economies, and they tend to be more important when explaining long-run trends as opposed to short-run fluctuations. Since 1990 to 2007 term premia dynamics exhibit a downward trend mostly explained by global expected inflation. Here we show the importance of a new factor explaining the yield curve and, especially, term premium dynamics: a global long-run risk factor related to future macroeconomic and financial risks, which is filtered as the third principal component of the international yield curves. Interestingly, this factor takes the center place when explaining the dynamics of the recent crisis. During this time, monetary policy has been extraordinarily expansionary, sharply and immediately lowering interest rate expectations. In future work, we intend to examine the term structure implications of the zero -or near zero- interest rate lower bound in the years beyond the sample period in this paper. Analyzing the international spillovers of these ongoing unconventional policies is definitely a worthwhile exercise. 
Table 1. Block Exogeneity Test

\begin{tabular}{lrr}
\hline \multicolumn{3}{c}{ Likelihood Ratio Test } \\
\hline Country & \multicolumn{1}{c}{ Stat. } & $p$-value \\
& & \\
JPN & 40.11 & 0 \\
UK & 106.81 & 0 \\
GER & 128.17 & 0 \\
SWI & 96.06 & 0 \\
CAN & 74.2 & 0 \\
AUS & 95.26 & 0 \\
NZL & 153.67 & 0 \\
\hline
\end{tabular}

Note: This table shows the p-values associated with the likelihood ratio statistics testing no-significance of global factors $F_{t}$ on domestic factors $X_{i t}$, as specified in our FAVAR term structure model. We apply the Sims (1980) correction on the likelihood ratio test, correcting degrees of freedom for the number of regressors per equation.

Table 2. Model Fit

\begin{tabular}{lr}
\hline \multicolumn{2}{c}{ Fit of Affine Term structure Model } \\
\hline Country & RMSE \\
JPN & 0.0212 \\
UK & 0.0606 \\
GER & 0.0214 \\
SWI & 0.0406 \\
CAN & 0.0371 \\
AUS & 0.0317 \\
NZL & 0.0155 \\
\hline
\end{tabular}

Note: This table shows the root mean square fitting error (square root of the minimized value of the objective function of the affine term structure model) for each country, in percentage points. 
Table 3. Variance Decomposition - Domestic Factors

\begin{tabular}{|c|c|c|c|c|c|c|c|c|c|c|c|c|c|}
\hline \multirow{4}{*}{$\begin{array}{l}\text { Country } \\
\text { JPN }\end{array}$} & \multirow{4}{*}{$\begin{array}{l}\text { Horizon } \\
\\
h=1 \\
h=40\end{array}$} & \multicolumn{4}{|c|}{ Domestic Level } & \multicolumn{4}{|c|}{ Domestic Slope } & \multicolumn{4}{|c|}{ Domestic Curvature } \\
\hline & & \multirow{2}{*}{$F_{\text {Growth }}^{\text {Glob }} 4.2$} & \multicolumn{2}{|l|}{$F_{\text {LRRisk }}^{\text {Glob }}$} & \multirow{2}{*}{$\begin{array}{r}\text { Global } \\
14.9\end{array}$} & \multirow{2}{*}{$F_{\text {Growth }}^{\text {Glob }}$} & $F_{\text {LRRisk }}^{\text {Glob }}$ & $F_{E x . I n f}^{G l o b}$ & \multirow{2}{*}{$\begin{array}{r}\text { Global } \\
2.7\end{array}$} & \multirow{2}{*}{$F_{\text {Growth }}^{\text {Glob }} 1.7$} & $F_{\text {LRRisk }}^{\text {Glob }}$ & $F_{E x . I n f}^{G l o b}$ & \multirow{2}{*}{$\begin{array}{l}\text { Global } \\
6.2\end{array}$} \\
\hline & & & 0.2 & 10.4 & & & 0.5 & 0.8 & & & 0 & 4.5 & \\
\hline & & 48.7 & 22.2 & 24.6 & 95.5 & 20.3 & 7.6 & 47.6 & 75.5 & 7 & 32.8 & 14.6 & 54.4 \\
\hline \multirow[t]{2}{*}{ CAN } & $\mathrm{h}=1$ & 17.4 & 7.3 & 20.7 & 44.8 & 2.3 & 0.2 & 1.5 & 3.9 & 9.4 & 6.8 & 8.1 & 24.2 \\
\hline & $\mathrm{h}=40$ & 23.1 & 52.1 & 23.4 & 98.6 & 17.5 & 26.1 & 8.8 & 52.4 & 9.3 & 47.9 & 6.5 & 63.7 \\
\hline \multirow[t]{2}{*}{ SWI } & $h=1$ & 0.2 & 8.4 & 43.7 & 52.4 & 0.4 & 0.4 & 5.56 & 6.3 & 0 & 3.1 & 3.4 & 6.5 \\
\hline & $h=40$ & 20.8 & 46.6 & 29.8 & 97.2 & 6.9 & 22.7 & 29.3 & 58.9 & 1.2 & 50.4 & 2 & 53.6 \\
\hline \multirow[t]{2}{*}{ GER } & $h=1$ & 4 & 8.8 & 56.1 & 68.9 & 0 & 0.1 & 2.5 & 2.7 & 0.7 & 4.1 & 27.5 & 32.4 \\
\hline & $h=40$ & 19.8 & 39.6 & 39.8 & 99.3 & 3.2 & 23.4 & 3.1 & 29.8 & 9.7 & 32.9 & 18.2 & 60.8 \\
\hline \multirow[t]{2}{*}{ AUS } & $h=1$ & 32.2 & 3.2 & 32.5 & 67.9 & 3.2 & 1.8 & 0.3 & 5.3 & 23.8 & 1.7 & 22.7 & 48.2 \\
\hline & $h=40$ & 36.6 & 35.1 & 26.6 & 98.4 & 29.5 & 5.9 & 20.9 & 56.2 & 21.9 & 21.6 & 19 & 62.6 \\
\hline \multirow[t]{2}{*}{ NZL } & $h=1$ & 51.8 & 5.4 & 24.7 & 82 & 0 & 0.2 & 0.4 & 0.5 & 5.8 & 0.1 & 2 & 8 \\
\hline & $\mathrm{h}=40$ & 45.6 & 32.6 & 20.1 & 98.4 & 11.9 & 37.8 & 3.6 & 53.3 & 7.7 & 6.9 & 2.2 & 16.7 \\
\hline \multirow[t]{2}{*}{ UK } & $h=1$ & 18.2 & 2 & 28.1 & 48.3 & 0 & 0.3 & 0.8 & 1.1 & 10.1 & 8.2 & 21.4 & 39.7 \\
\hline & $h=40$ & 27 & 44.4 & 27.4 & 98.8 & 6.5 & 53.2 & 1.6 & 61.3 & 5 & 65 & 15.1 & 85.1 \\
\hline \multirow[t]{2}{*}{ Avg. } & $h=1$ & 18.3 & 5.1 & 30.8 & 54.2 & 1 & 0.5 & 1.7 & 3.2 & 7.4 & 3.4 & 12.8 & 23.6 \\
\hline & $h=40$ & 31.7 & 38.9 & 27.4 & 98 & 13.7 & 25.2 & 16.4 & 55.3 & 8.8 & 36.8 & 11.1 & 56.7 \\
\hline
\end{tabular}

Note: This table shows the contribution of shocks to the three global shocks $F_{\text {Growth }}^{\text {Glob }}, F_{\text {LRRisk }}^{\text {Glob }}, F_{\text {Growth }}^{\text {Ex.In }}$ to the variance of the three local factors (level, slope and curvature) contained in $X_{i t}$. Results are reported for all countries in the sample and for selected horizons of 1 and 40 periods. 
Table 4. Variance Decomposition - Yields

\begin{tabular}{|c|c|c|c|c|c|c|c|c|c|c|c|}
\hline \multirow[t]{2}{*}{ Country } & \multirow[t]{2}{*}{ Horizon } & \multicolumn{5}{|c|}{3 months yields } & \multicolumn{5}{|c|}{10 years yields } \\
\hline & & $F_{\text {Growth }}^{\text {Glob }}$ & & & Global & Local & $F_{\text {Growth }}^{\text {Glob }}$ & $F_{\text {LRRisk }}^{\text {Glob }}$ & $F_{E x . I n f}^{G l o b}$ & Global & Local \\
\hline \multirow[t]{2}{*}{ JPN } & $\mathrm{h}=1$ & 7 & 1.31 & 6.88 & 15.19 & 84.81 & 2.2 & 0.06 & 9.46 & 11.71 & 88.29 \\
\hline & $\mathrm{h}=40$ & 71.49 & 11.31 & 5.56 & 88.36 & 11.64 & 26.55 & 24.72 & 44.33 & 95.59 & 4.41 \\
\hline \multirow[t]{2}{*}{ CAN } & $\mathrm{h}=1$ & 8.26 & 1.58 & 9.38 & 19.22 & 80.78 & 11.73 & 5.5 & 15.15 & 32.38 & 67.62 \\
\hline & $\mathrm{h}=40$ & 25.87 & 52.68 & 15.72 & 94.27 & 5.73 & 21.7 & 44.97 & 29.51 & 96.18 & 3.82 \\
\hline \multirow[t]{2}{*}{ SWI } & $\mathrm{h}=1$ & 0.79 & 3.09 & 19.95 & 23.82 & 76.17 & 0.07 & 6.55 & 42.43 & 49.05 & 50.95 \\
\hline & $\mathrm{h}=40$ & 25.23 & 52.36 & 6.07 & 83.66 & 16.34 & 13.54 & 23.44 & 59.8 & 96.78 & 3.22 \\
\hline \multirow[t]{2}{*}{ GER } & $\mathrm{h}=1$ & 2.76 & 2.55 & 12.58 & 17.89 & 82.11 & 3.12 & 7.75 & 53.69 & 64.56 & 35.44 \\
\hline & $\mathrm{h}=40$ & 14.9 & 44.9 & 22.01 & 81.81 & 18.19 & 19.49 & 23.4 & 40.64 & 83.53 & 16.47 \\
\hline \multirow[t]{2}{*}{ AUS } & $\mathrm{h}=1$ & 26.19 & 5.06 & 19.5 & 50.75 & 49.25 & 25.37 & 2.07 & 28.74 & 56.18 & 43.82 \\
\hline & $\mathrm{h}=40$ & 49.13 & 30.16 & 16.32 & 95.61 & 4.39 & 31.44 & 34.77 & 30.82 & 97.03 & 2.97 \\
\hline \multirow[t]{2}{*}{ NZL } & $\mathrm{h}=1$ & 18.33 & 1.81 & 7.24 & 27.38 & 72.62 & 41.76 & 5.21 & 22.22 & 69.19 & 30.81 \\
\hline & $\mathrm{h}=40$ & 41.16 & 43.68 & 7.05 & 91.89 & 8.11 & 41.61 & 21.01 & 28.48 & 91.1 & 8.9 \\
\hline \multirow[t]{2}{*}{ UK } & $\mathrm{h}=1$ & 5.96 & 0.24 & 3.65 & 9.85 & 90.15 & 16.73 & 1.87 & 29.62 & 48.22 & 51.78 \\
\hline & $\mathrm{h}=40$ & 25.52 & 55.31 & 11.87 & 92.7 & 7.3 & 29.71 & 27.62 & 37.87 & 95.2 & 4.8 \\
\hline \multirow[t]{2}{*}{ Average } & $\mathrm{h}=1$ & 9.9 & 2.23 & 11.31 & 23.44 & 76.56 & 14.43 & 4.14 & 28.76 & 47.33 & 52.67 \\
\hline & $\mathrm{h}=40$ & 36.19 & 41.49 & 12.09 & 89.77 & 10.23 & 26.29 & 28.56 & 38.78 & 93.63 & 6.37 \\
\hline
\end{tabular}

Note: This table shows the contribution of shocks to the three global shocks $F_{\text {Growth }}^{G l o b}, F_{\text {LRRisk }}^{\text {Glob }}$, $F_{\text {Growth }}^{\text {Ex.Inf }}$, their sum and the contribution of the three local factors (level, slope and curvature) contained in $X_{i t}$ to the variance of 3 months and 10 year yields. Results are reported for all countries in the sample and for selected horizons of 1 and 40 periods. 
Table 5. Variance Decomposition - Term Premia

\begin{tabular}{l|rrrrr} 
Country & \multicolumn{5}{|c}{ Term Premia $(\mathrm{h}=40)$} \\
\hline \hline & $F_{\text {Growth }}^{\text {Glob }}$ & $F_{\text {LRRisk }}^{\text {Glob }}$ & \multicolumn{1}{c}{$F_{\text {Ex.Inf }}^{\text {Glob }}$} & Global & \multicolumn{1}{c}{ Local } \\
\hline JPN & 11.4 & 10.13 & 66.19 & 87.72 & 12.28 \\
CAN & 2.82 & 81.9 & 1.82 & 86.54 & 13.46 \\
SWI & 7.72 & 70.02 & 8.21 & 85.95 & 14.05 \\
GER & 3.18 & 60.79 & 1.55 & 65.52 & 34.48 \\
AUS & 19.87 & 35.82 & 31.43 & 87.12 & 12.88 \\
NZL & 0.96 & 85.22 & 3.43 & 89.61 & 10.39 \\
UK & 0.56 & 90.73 & 0.87 & 92.16 & 7.84 \\
Avg & 6.64 & 62.09 & 16.21 & 84.94 & 15.06 \\
\hline \hline
\end{tabular}

Note: This table shows the contribution of shocks to the three global shocks $F_{\text {Growth }}^{\text {Glob }} F_{\text {LRRisk }}^{\text {Glob }}$, $F_{\text {Growth }}^{\text {Ex.Inf }}$, their sum and the contribution of the three local factors (level, slope and curvature) contained in $X_{i t}$ to the variance of the term premia. Results are reported for all countries in the sample and for the 40 periods ahead horizon.

Table 6. Variance Decomposition - Forward and Risk Neutral Rates

\begin{tabular}{|c|c|c|c|c|c|c|c|c|c|c|}
\hline \multirow[t]{2}{*}{ Country } & \multicolumn{5}{|c|}{ Forward rates $(h=40)$} & \multicolumn{5}{|c|}{ Risk neutral rates $(h=40)$} \\
\hline & $F_{\text {Growth }}^{\text {Glob }}$ & $F_{L R R i s k}^{\text {Glob }}$ & $F_{E x . I n f}^{G l o b}$ & Global & Local & $F_{\text {Growth }}^{\text {Glob }}$ & $F_{\text {LRRisk }}^{\text {Glob }}$ & $F_{E x . I n f}^{G l o b}$ & Global & Local \\
\hline JPN & 11.16 & 22.56 & 58.60 & 92.32 & 7.68 & 37.26 & 55.92 & 3.76 & 96.93 & 3.07 \\
\hline CAN & 19.85 & 34.32 & 35.69 & 89.86 & 10.14 & 9.19 & 79.89 & 10.89 & 99.97 & 0.03 \\
\hline SWI & 3.83 & 1.88 & 75.68 & 81.39 & 18.61 & 11.57 & 82.62 & 0.03 & 94.22 & 5.78 \\
\hline GER & 11.05 & 4.33 & 21.58 & 36.98 & 63.02 & 7.70 & 75.23 & 10.33 & 93.16 & 6.84 \\
\hline AUS & 27.82 & 33.35 & 33.58 & 94.75 & 5.25 & 10.20 & 81.20 & 8.59 & 99.99 & 0.01 \\
\hline NZL & 33.26 & 11.66 & 33.68 & 78.60 & 21.40 & 7.89 & 84.52 & 7.58 & 99.99 & 0.01 \\
\hline UK & 29.29 & 10.92 & 44.09 & 84.30 & 15.70 & 7.80 & 82.31 & 9.82 & 99.93 & 0.07 \\
\hline Avg & 19.47 & 17.00 & 43.27 & 79.74 & 20.26 & 13.09 & 77.38 & 7.29 & 97.74 & 2.26 \\
\hline
\end{tabular}

Note: This table shows the contribution of shocks to the three global shocks $F_{\text {Growth }}^{\text {Glob }}, F_{\text {LRRisk }}^{\text {Glob }}$, $F_{\text {Growth }}^{\text {Ex.Inf }}$, their sum and the contribution of the three local factors (level, slope and curvature) contained in $X_{i t}$ to the variance of the forward interest rates and the risk neutral interest rates. Results are reported for all countries in the sample and for the 40 periods ahead horizon. 
Table 7. Variance Decomposition - Robustness to Bias Correction

Term Premia: variance decomposition with and without bias correction

\begin{tabular}{|c|c|c|c|c|c|c|c|c|}
\hline & \multicolumn{8}{|c|}{ horizon $=40$} \\
\hline & \multicolumn{2}{|l|}{$F_{\text {Growth }}^{\text {Glob }}$} & \multicolumn{2}{|l|}{$F_{\text {LRRisk }}^{\text {Glob }}$} & \multicolumn{2}{|l|}{$F_{E x . I n f}^{G l o b}$} & \multicolumn{2}{|l|}{$\begin{array}{l}\text { Global } \\
\text { shocks }\end{array}$} \\
\hline & ols & & ols & $c$ & ols & $c$ & ols & bc \\
\hline JPN & 6.5 & 11.4 & 8.68 & 10.13 & 69.23 & 66.19 & 84.41 & 87.72 \\
\hline CAN & 12.13 & 2.82 & 17.65 & 81.9 & 34.83 & 1.82 & 64.61 & 86.54 \\
\hline SWI & 9.39 & 7.72 & 44.14 & 70.02 & 21.54 & 8.21 & 75.06 & 85.95 \\
\hline GER & 5.15 & 3.18 & 41.05 & 60.79 & 2.19 & 1.55 & 48.38 & 65.52 \\
\hline AUS & 26.29 & 19.87 & 17.74 & 35.82 & 41.5 & 31.43 & 85.53 & 87.12 \\
\hline NZL & 15.15 & 0.96 & 36.85 & 85.22 & 17.14 & 3.43 & 69.14 & 89.61 \\
\hline UK & 6.12 & 0.56 & 43.55 & 90.73 & 20.72 & 0.87 & 70.38 & 92.16 \\
\hline Avg. & 11.53 & 6.64 & 29.95 & 62.09 & 29.59 & 16.21 & 70.28 & 84.94 \\
\hline
\end{tabular}

Note: This table shows the contribution of shocks to the three global shocks $F_{\text {Growth }}^{\text {Glob }}, F_{\text {LRRisk }}^{\text {Glob }}, F_{\text {Growth }}^{\text {Ex.Inf }}$ and of their sum to the variance of the term premia. The table shows: (i) results obtained estimating the model through OLS and (ii) results obtained using the inverse bootrap bias correction as in Bauer, Rudebusch and Wu, 2012. Results are reported for all countries in the sample and for the 40 periods ahead horizon.

Table 8. Variance Decomposition - Term Premia - Subsample 1990Q1-2007Q2

\begin{tabular}{l|rrrrr} 
Country & \multicolumn{5}{|c}{ Term Premia (h=40) } \\
\hline \hline & \multicolumn{1}{|c}{$F_{\text {Growth }}^{\text {Glob }}$} & \multicolumn{1}{c}{$F_{\text {LRRisk }}^{\text {Glob }}$} & \multicolumn{1}{l}{$F_{\text {Ex.Inf }}^{\text {Glob }}$} & Global & \multicolumn{1}{l}{ Local } \\
& 7.67 & 33.52 & 52.46 & 93.66 & 6.34 \\
\hline JPN & 20.27 & 5.12 & 54.61 & 80.01 & 19.99 \\
CAN & 2.94 & 0.37 & 66.91 & 70.22 & 29.78 \\
SWI & 15.64 & 11.12 & 5.05 & 31.8 & 68.2 \\
GER & 32.8 & 12.96 & 49.37 & 95.13 & 4.87 \\
AUS & 30.5 & 2.17 & 55.28 & 87.95 & 12.05 \\
NZL & 12.83 & 23.39 & 47.39 & 83.61 & 16.39 \\
UK & 17.52 & 12.65 & 47.3 & 77.47 & 22.53 \\
Avg & & & & &
\end{tabular}

Note: This table shows the contribution of shocks to the three global shocks $F_{\text {Growth }}^{\text {Glob }}, F_{\text {LRRisk }}^{\text {Glob }}, F_{\text {Growth }}^{\text {Ex.Inf }}$, their sum and the contribution of the three local factors (level, slope and curvature) contained in $X_{i t}$ to the variance of the term premia when the model is estimated for the period 1990Q1-2007Q2 only. Results are reported for all countries in the sample and for the 40 periods ahead horizon. 
Table 9. Variance Decomposition - Term Premia - US as Global Factor

\begin{tabular}{l|rrrrr} 
Country & \multicolumn{5}{|c}{ Term Premia (h=40) } \\
\hline \hline & $F_{\text {Growth }}^{\text {Glob }}$ & $F_{\text {LRRisk }}^{\text {Glob }}$ & $F_{\text {Ex.Inf }}^{\text {Glob }}$ & Global & \multicolumn{1}{c}{ Local } \\
\hline JPN & 28.76 & 26.23 & 25.30 & 80.29 & 19.71 \\
CAN & 35.30 & 26.66 & 30.77 & 92.73 & 7.27 \\
SWI & 43.55 & 32.43 & 14.14 & 90.12 & 9.88 \\
GER & 3.57 & 52.20 & 2.96 & 58.73 & 41.27 \\
AUS & 22.49 & 35.69 & 30.74 & 88.92 & 11.08 \\
NZL & 29.29 & 26.72 & 24.98 & 80.99 & 19.01 \\
UK & 17.73 & 36.95 & 24.71 & 79.39 & 20.61 \\
Avg & 25.81 & 33.84 & 21.94 & 81.60 & 18.40 \\
\hline \hline
\end{tabular}

Note: This table shows the contribution of shocks to the three global shocks $F_{\text {Growth }}^{\text {Glob }} F_{\text {LRRisk }}^{\text {Glob }}$, $F_{\text {Growth }}^{\text {Ex.Inf }}$, their sum and the contribution of the three local factors (level, slope and curvature) to the variance of the term premia when the global factors are substituted with the first three principal components of the US yield curve. Results are reported for all countries in the sample and for the 40 periods ahead horizon. 
Figure 1. National Yield Curves
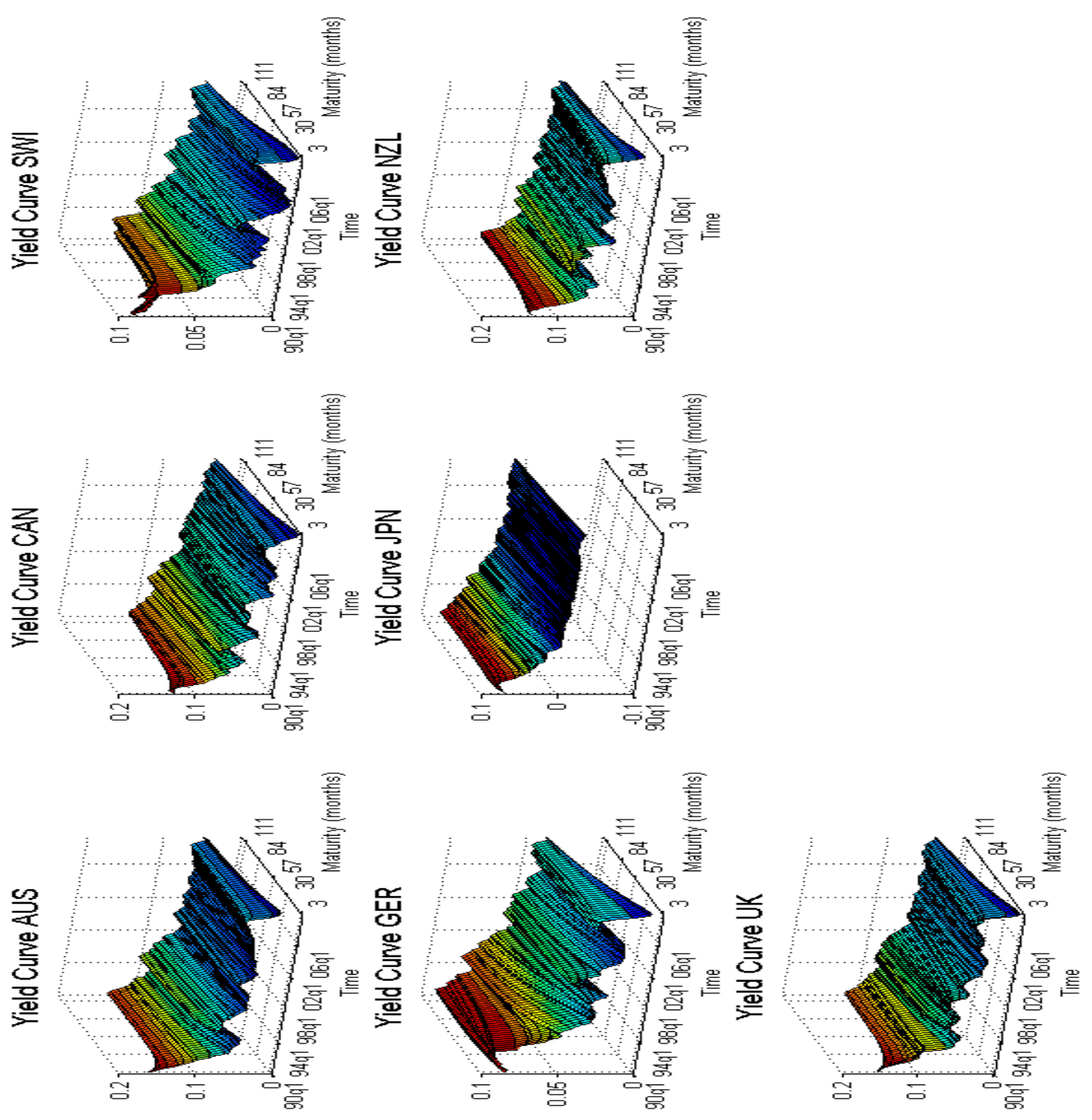

Note: This figure shows the evolution of the yield curves across countries. 
Figure 2. National Yield Curves - First Three Factors
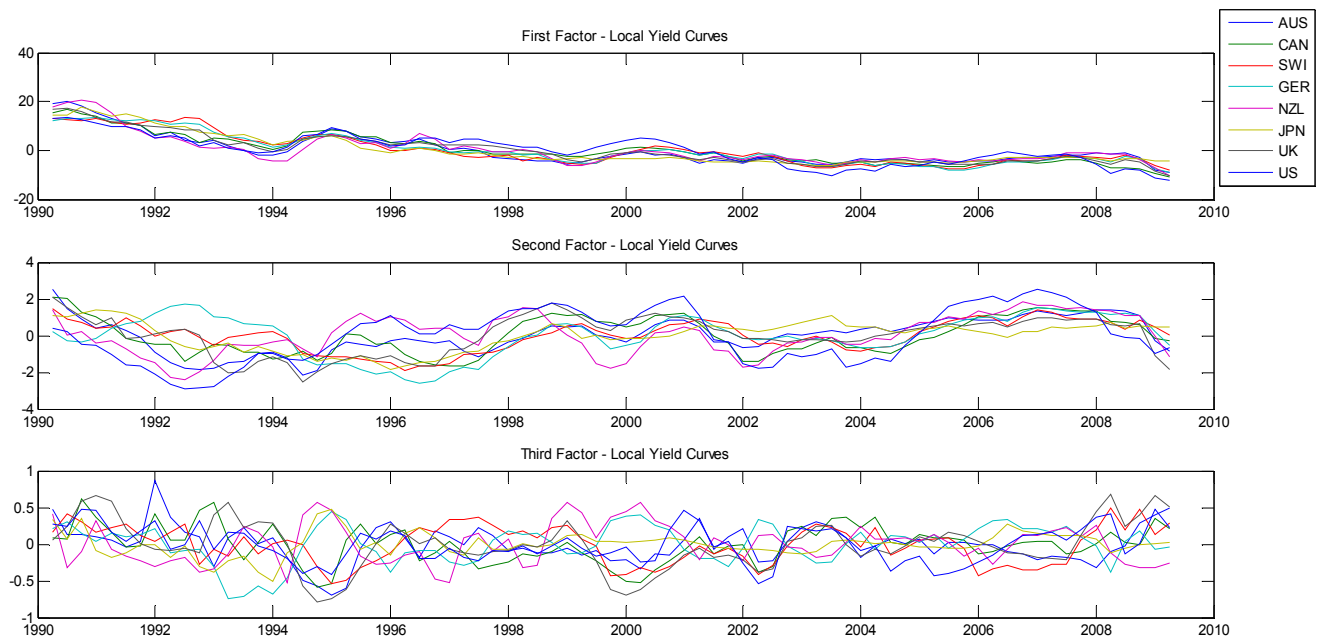

Note: This figure shows the "level", "slope" and "curvature" factors for all the countries in our sample. Level, slope and curvature are computed as the first, second and third principal components extracted from the crosssection of the yields of each country.

\section{Figure 3. First and Second Global Factors Dynamics}
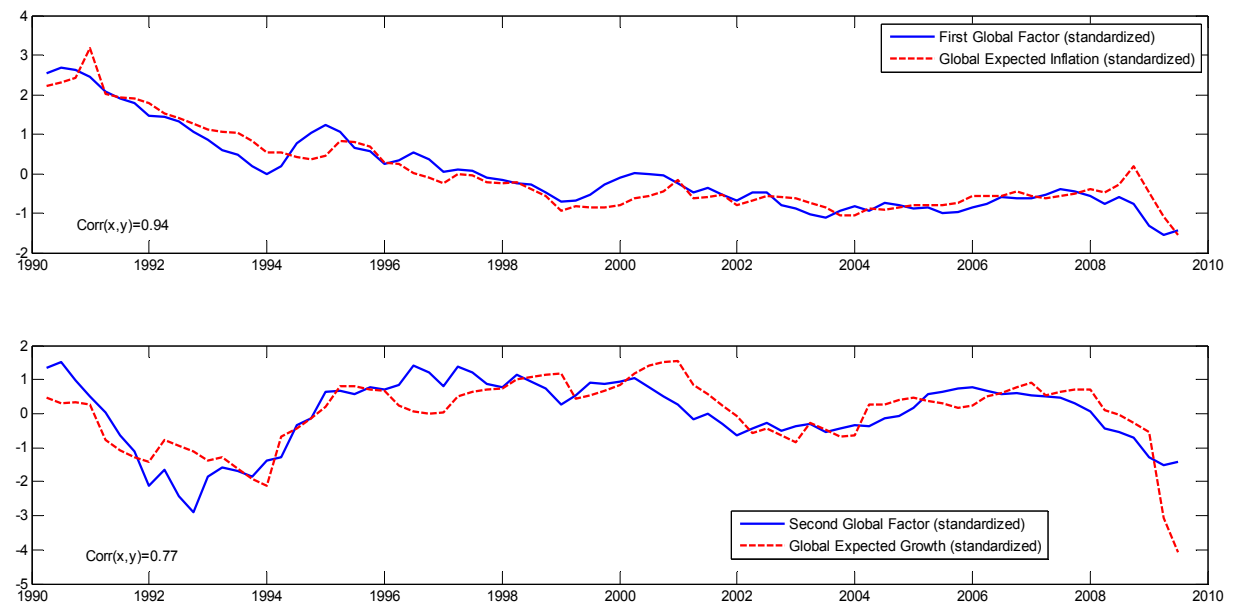

Note: This figure shows the first two global factors plotted against their macroeconomic interpretations. The first global factor is plotted against the first principal component extracted from a matrix containing data on expected inflation for OECD countries. The second global factor is plotted against the first principal component extracted from a matrix containing data on real activity for OECD countries. 
Figure 4. Third Global Factor Dynamics
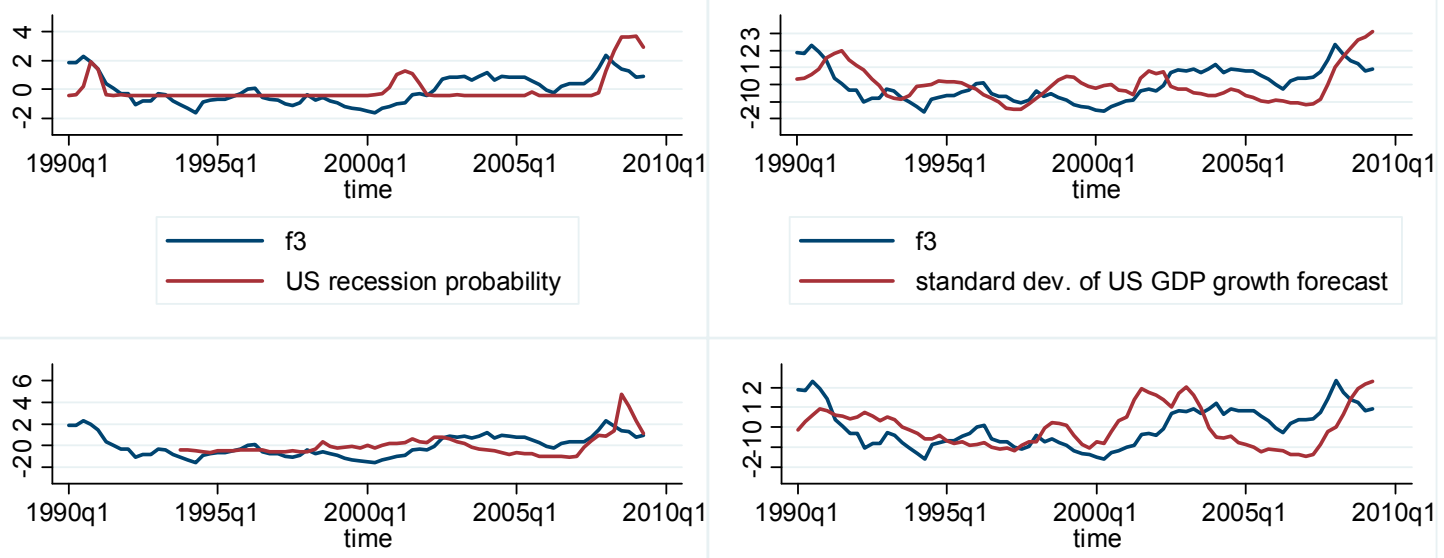

f3

f3

financial stress index (St. Louis Fed)

Policy Uncertainty (Baker et al. 2013)
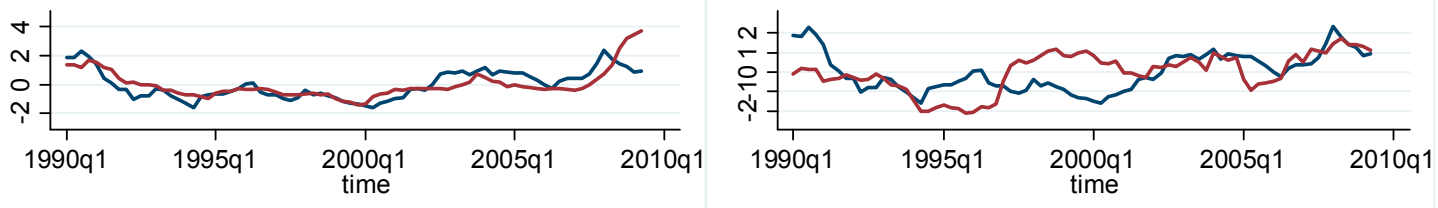

f3

f3

standard dev. of US inflation forecast

skewness of US inflation forecast - inverted

Note: This figure shows the third global factor plotted against a series of macroeconomics and financial variables. In the top two panels the third factor is plotted against the US recession probabilities (left panel) and the standard deviation of the one year ahead forecasts of US GDP growth (right panel). The recession probabilities series has been constructed by Chauvet and Piger (source: St. Louis Fed database). The standard deviation of US GDP forecast is computed from the point forecasts of one year ahead real GDP growth published by the Economist Intelligence Unit. The central panel report the third global factor plotted against the financial stress index published by the St. Louis Fed (left panel) and policy uncertainty index constructed by Baker et al. (2013) (right panel). The bottom two panels show the third global factor plotted against the standard deviation of one year ahead forecasts of US CPI inflation (left) and against the skewness of that same series. Data for these two graphs are taken from the Economist Intelligence Unit. 
Figure 5. Global Yield Curve (2007-08)
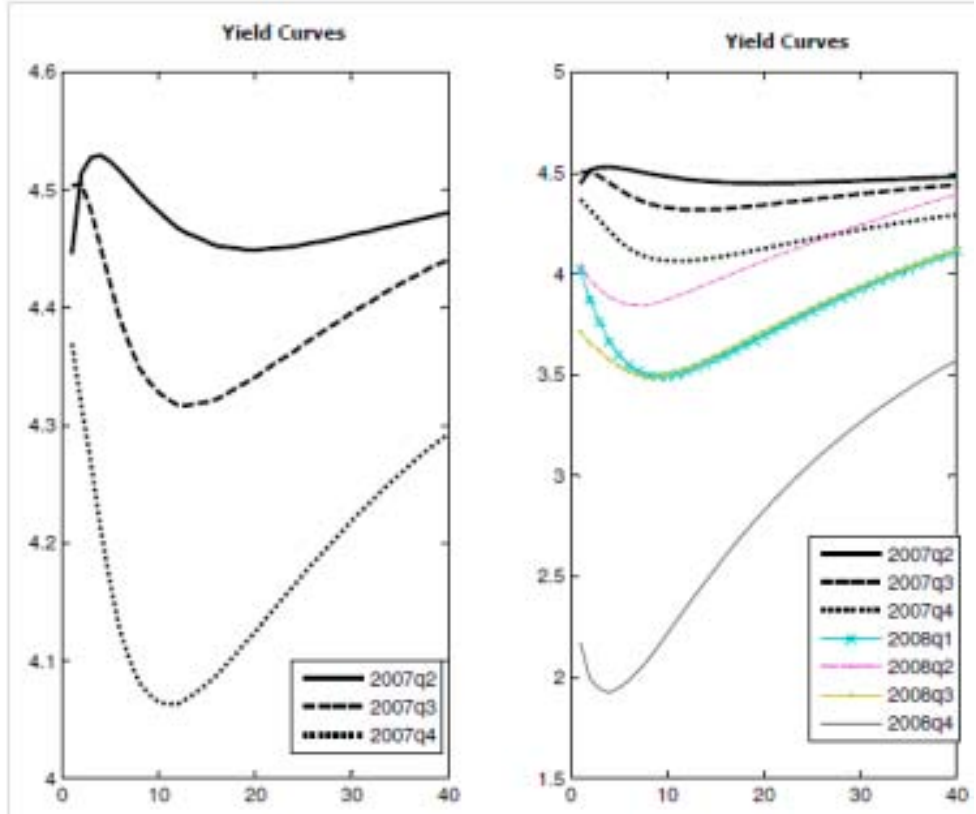

Note: This figure shows the global yield curves during the 2007 and 2008. The global yield curve is constructed as the equally-weighted average of the country-yield curves in sample. Yield maturities are in quarters. 
Figure 6. Responses of Local Yield Factors to Global Factors in the UK
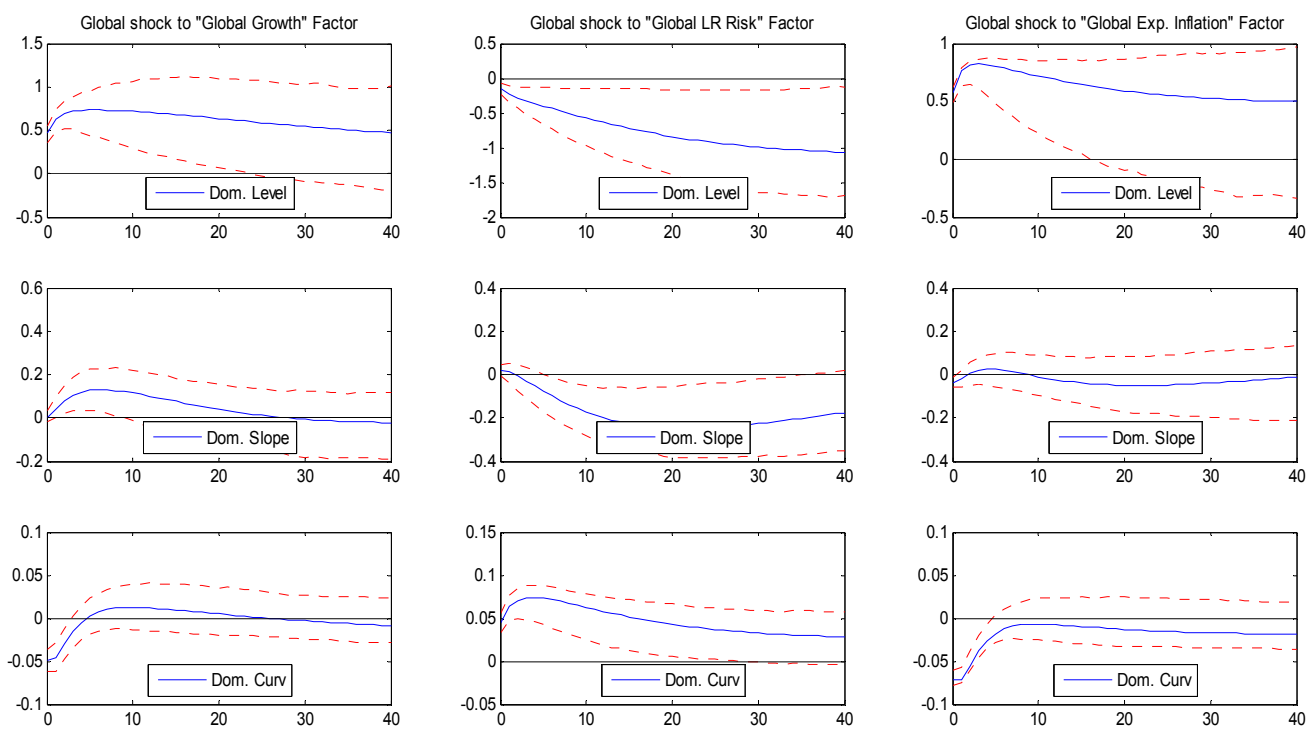

Note: This figure shows the responses of the three local factors (level, slope and curvature) contained in $X_{i t}$ to shocks to the three global factors. Impulse responses are plotted for an horizon of 40 periods. Dashed lines represent a 95 percent confidence interval. Results are reported for the UK only. 
Figure 7. Contribution of Global Shocks to the Yield Curves Dynamics
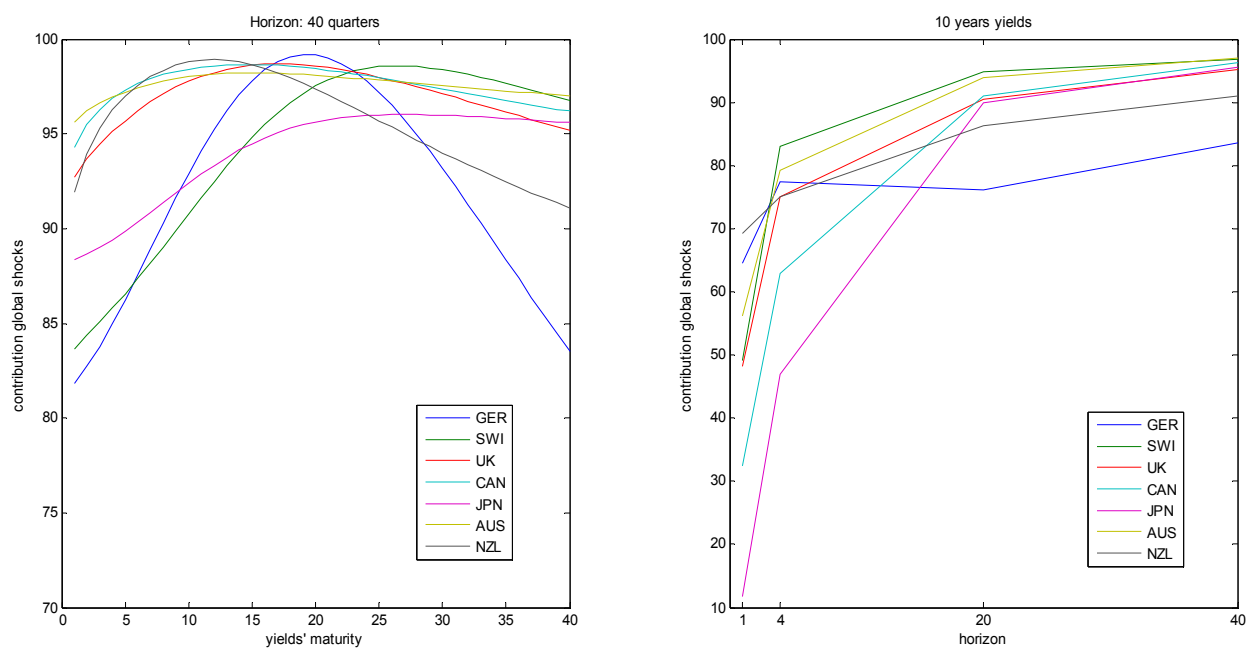

Note: This figure shows the contribution of global shocks to the variance of domestic yields across both maturities (left panel) and forecasting horizon (right panel). Results are shown for all the countries in our sample. 


\section{Figure 8. Term Premia Dynamics}
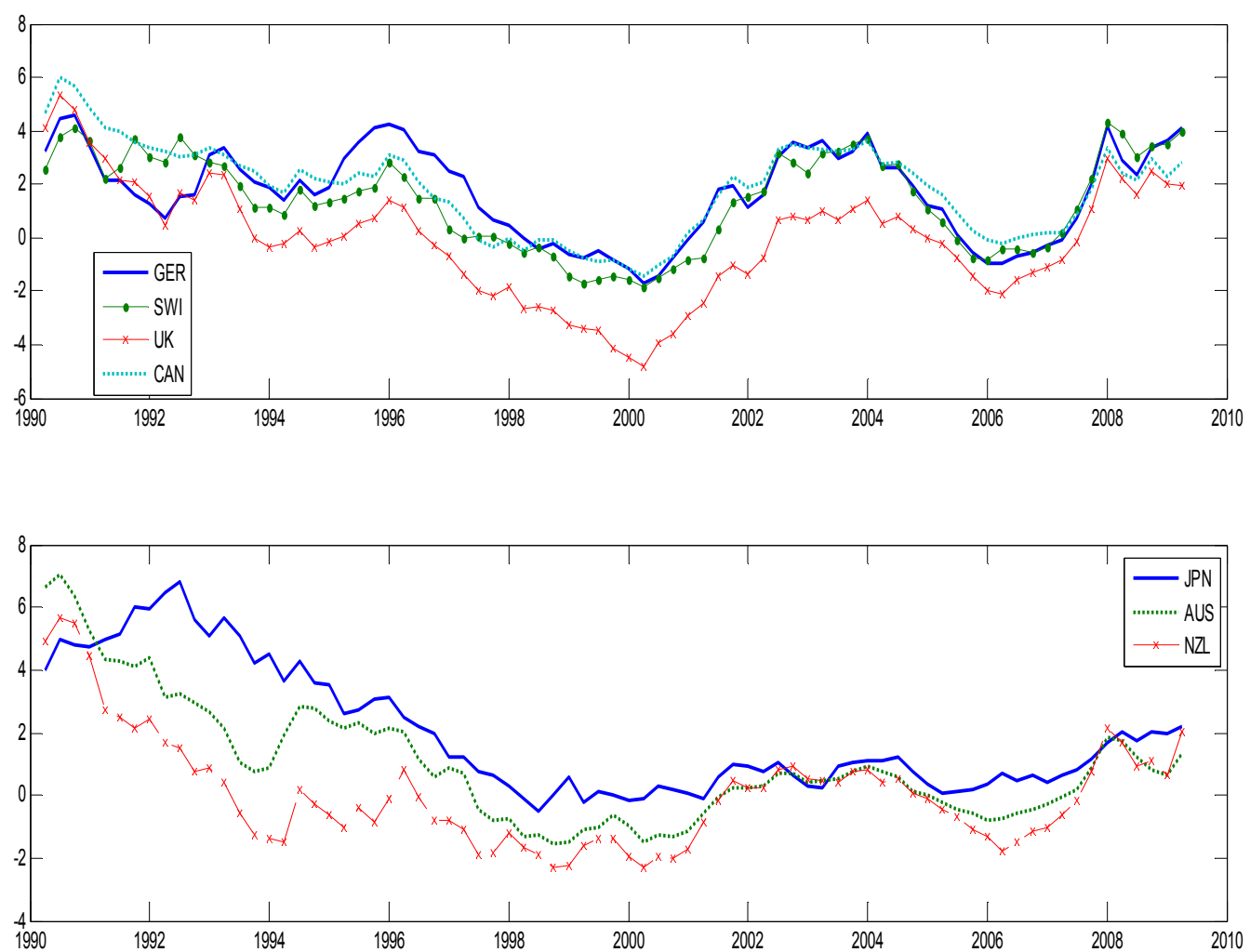

Note: This figure shows the dynamics of the term premia for all of the countries in our sample. Term premia are computed as the difference between the model implied 5 -year forward rates 5 years from now and the average expected one year rate 5 to 10 years from now. 
Figure 9. Historical Decomposition: Contribution of Local and Global Shocks to Term Premia Dynamics
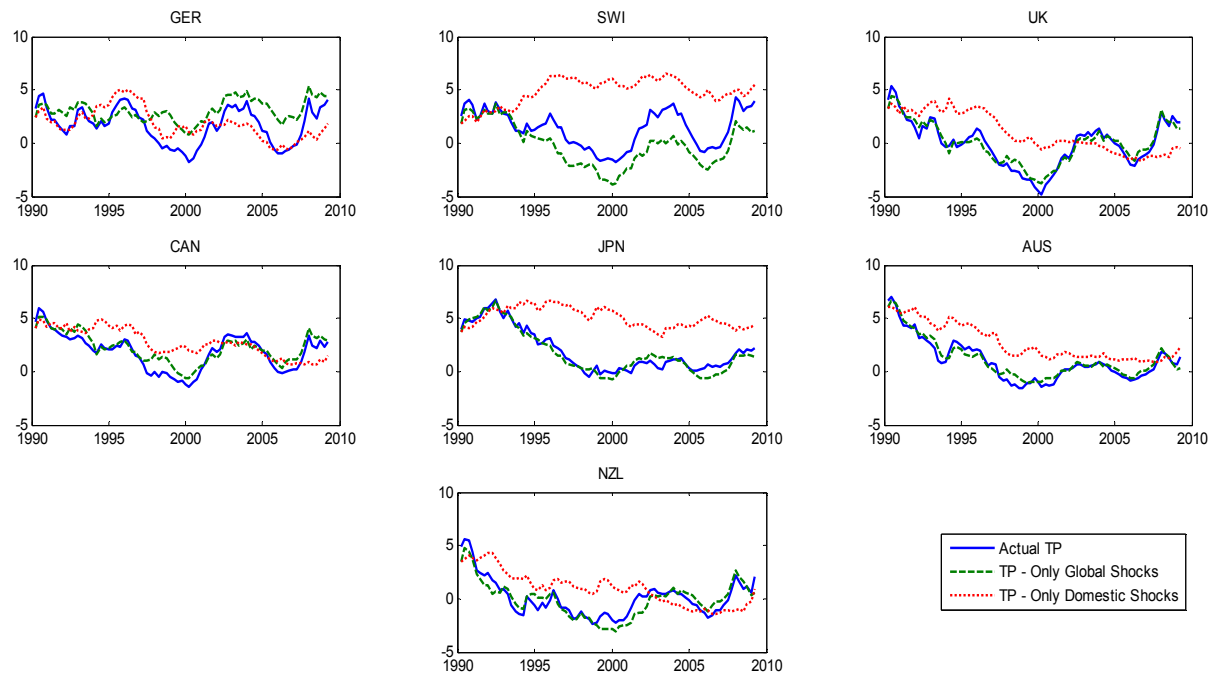

Note: This figure shows the dynamics of the estimated term premia plotted together with two counterfactual term premia derived under the assumptions that: (i) the only existing shocks are those to the global factors $F_{t}$ and (ii) the only existing shocks are those to the local factors $X_{i t}$. 
Figure 10. Impulse Responses of the Term Premia to Global Shocks
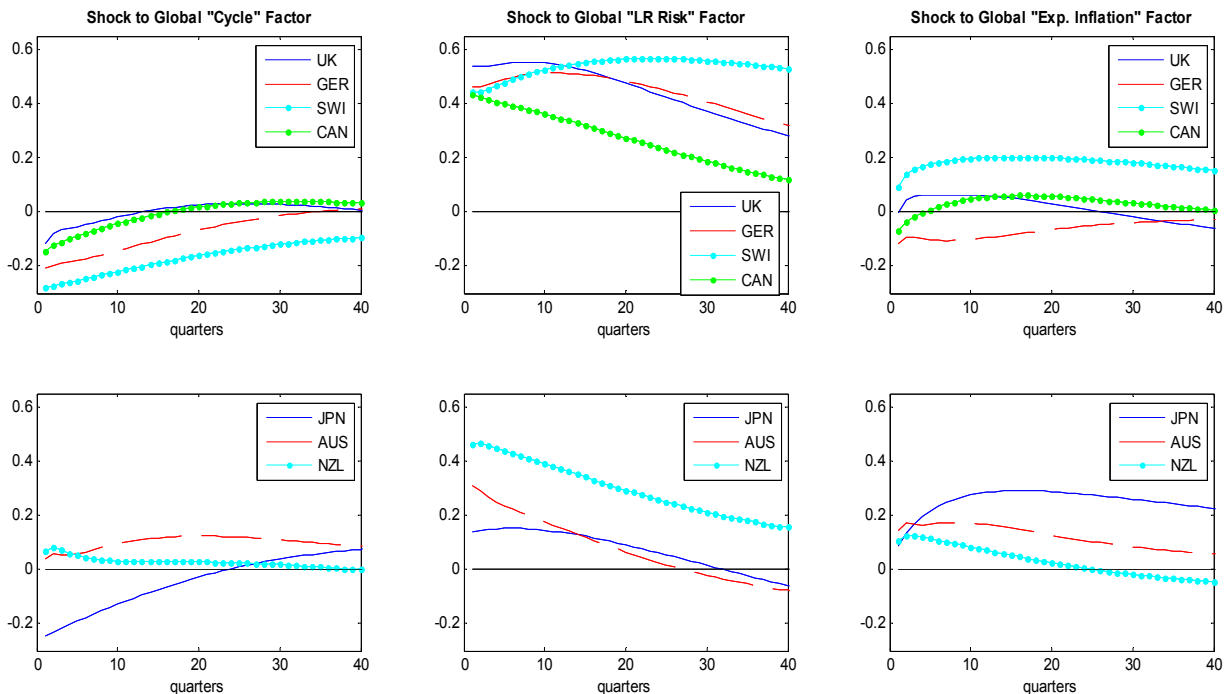

Note: This figure shows the dynamic responses of the term premia to shocks to the three global factors (global level, global slope and global curvature) contained in $F_{t}$. Results are reported for all of the countries in the sample and for forecasting horizons of up to 40 quarters. 
Figure 11. Contribution of Global Shocks to the Term Premium Dynamics - Japan
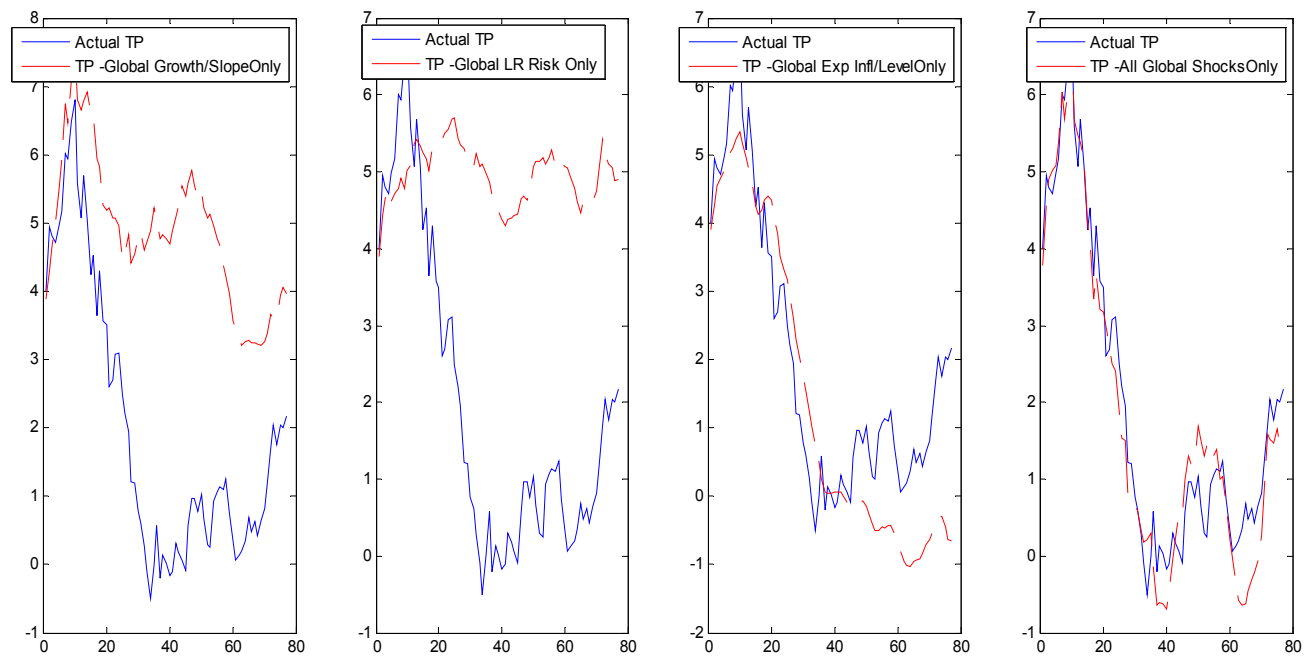

Note: This figure shows the term premium plotted against the one generated by different historical decompositions in which only one of the three global shocks exists (first three panels starting from the left) and in which all of the three global shocks exist (right panel). Results are presented for Japan. 
Figure 12. Contribution of Global Shocks to the Term Premium Dynamics - UK
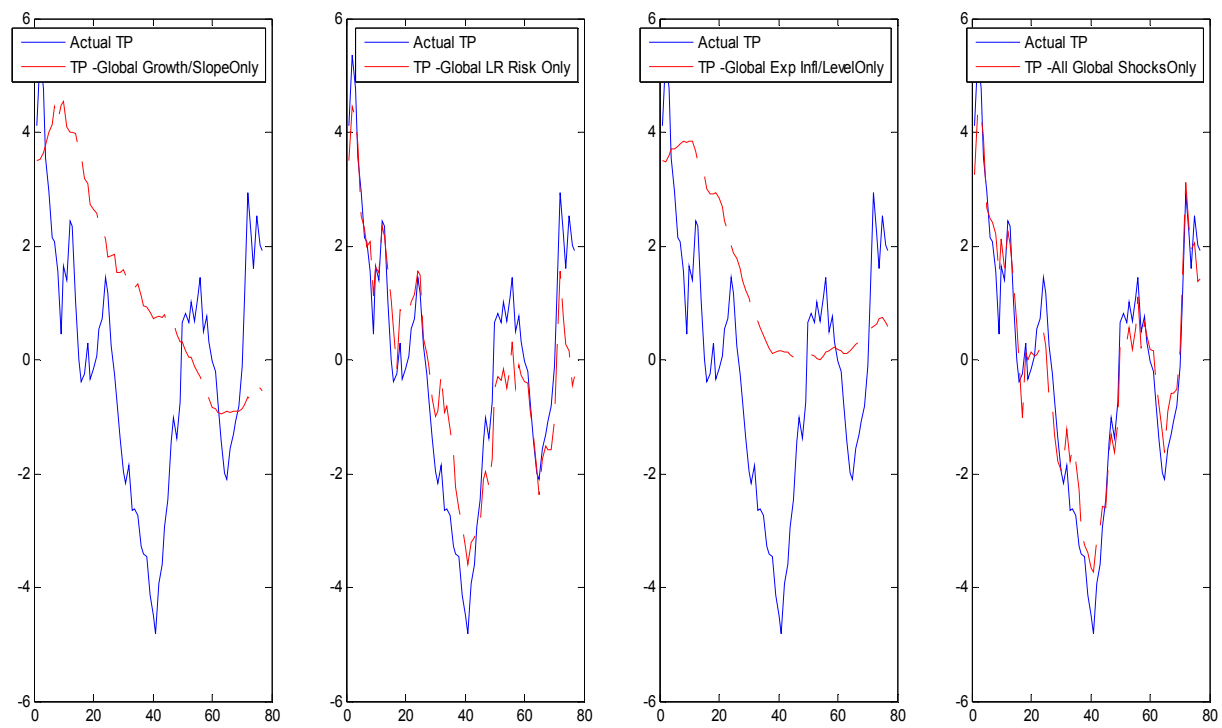

Note: This figure shows the term premium plotted against the one generated by different historical decompositions in which only one of the three global shocks exists (first three panels starting from the left) and in which all of the three global shocks exist (right panel). Results are presented for the UK. 


\section{REFERENCES}

Abbritti, M., Gil-Alana, L., Lovcha, Y., and Moreno, A., 2012, "Term Premim Persistence," School of Economics and Business Administration, University of Navarra, Working Paper No. 26, 2012.

Antonio, A., Agnello, L., Furcieri, D., and Sousa, R., 2011, "Assessing Long-Term Fiscal Developments: A New Approach," Journal of International Money and Finance, 30 (2011), pp. 130-146.

Ang, A., and Piazzesi, M, 2003, “ A No-Arbitrage Vector Autoregression of Term Structure Dynamics with Macroeconomic and Latent Variables," Journal of Monetary Economics, Elsevier, Vol. 50(4), pp. 745-787, May.

Bauer, G., Rios, A., 2012, “An International Dynamic Term Structure Model with Economic Restrictions and Unspanned Risks," Working Papers 12-5, Bank of Canada.

Bauer, M., Rudebusch, G., and Wu, J., 2012, "Correcting Estimation Bias in Dynamic Term Structure Models," Journal of Business \& Economic Statistics, 2012, Vol 30 (3), pp. 454-467.

, Rudebusch, G., and Wu, J., 2013, "Comment on "Term Premia and Inflation Uncertainty: Empirical Evidence from an International Panel Dataset," Forthcoming, American Economic Review.

Baker, S., Bloom, N., and Davis, S., 2013, “Measuring Economic Policy Uncertainty,” MIMEO Stanford University.

Geert, B, Cho, S., and Moreno, A., 2010, "New Keynesian Macroeconomics and the Term Structure," Journal of Money, Credit and Banking, Blackwell Publishing, Vol. 42(1), pp. 33-62, 02.

Bernanke, B., 2006, "Remarks before the Economic Club of New York," New York March 20, 2006.

Bernanke, B., Boivin, J., and Eliasz, P., 2005, "Measuring the Effects of Monetary Policy: A Factor-augmented Vector Autoregressive (FAVAR) Approach," The Quarterly

Journal of Economics, MIT Press, Vol. 120(1), pp. 387-422, January.

Campbell, J., Sunderam, A., and Viceira, L., 2013, "Inflation Bets or Deflation Hedges? The Changing Risks of Nominal Bonds," Working Paper, MIMEO Harvard University.

Cochrane, J., and Piazzesi, M., 2008, “Decomposing the Yield Curve,” Working Paper, MIMEO University of Chicago.

Dahlquist, M, and Hasseltoft, H, 2012, “International Bond Risk Premia,” Forthcoming, Journal of International Economics. 
Dell'Erba, S, and Sola, S., 2013, "Fiscal Policy, Interest Rateds and Risk Premia in Open Economy," IHEID Working Papers 5-2013, Economics Section, The Graduate Institute of International Studies.

Diebold, F., Li, C., and Yue, V., 2008, "Global Yield Curve Dynamics and Interactions: A Dynamic Nelson-Siegel Approach,” Journal of Econometrics, 146(2), pp. 351-363.

Duffee, G., 2011, "Information In (And Not In) The Term Structure," Review of Financial Studies 24, pp. 2895-2934.

Fleckenstein, M., Longstaff, F., and Lustig, H., 2013, “Deflation Risk," NBER Working Paper N. 19238, July 2013.

Forni, M., Giannone, D., Lippi, M., and Reichlin, L., 2009, “Opening The Black Box: Structural Factor Models With Large Cross Sections," Econometric Theory, Cambridge University Press, Vol. 25(05), pp. 1319-1347, October.

Geweke, J., 1977, “The Dynamic Factor Analysis of Economic Time Series Models," Latent Variables in Socioeconomic Models, Amsterdam, North Holland, pp. 365-383.

Gil-Alana, L., and Moreno, A., 2012, "Uncovering the US Term Premium: An Alternative Route," Journal of Banking and Finance, 36, pp. 1181-1193.

Gürkaynak, R., Sack, B., and Wright, J., 2007, “The U.S. Treasury Yield Curve: 1961 to the Present," Journal of Monetary Economics, 54, pp. 2291-2304.

Hellerstein, R., 2011, “Global Bond Risk Premiums," Federal Reserve Bank of New York Staff Reports, Staff Report No. 499, June 2011.

Jotikashtira, C., Le, A., and Lundblad, C., 2012, "Why Do Term Structures in Different Countries Comove," MIMEO, University of North Carolina.

Joslin, S., Priebsch, M., and Singleton, K., 2012, “ Risk-Premiums in Dynamic Term Structure Models with Unspanned Macro Risks,” MIMEO, Stanford University.

Joslin, S., Singleton, K., and Haoxiang Zhu, 2011, "A New Perspective on Gaussian Dynamic Term Structure Models,” Review of Financial Studies 24(3), pp. 926-970.

Kilian, L., 1998, “ Small-Sample Confidence Intervals for Impulse Response Functions," Review of Economics and Statistics, 1998, 80 (2), pp. 218-230.

Ludvigson, S., and Ng, S., 2009, "Macro Factors in Bond Risk Premia," Review of Financial Studies, Oxford University Press for Society for Financial Studies, Vol. 22(12), pp. 5027-5067, December.

Moench, E., 2008, "Forecasting the Yield Curve in a Data-Rich Environment: A No Arbitrage Factor Augmented VAR Approach," Journal of Econometrics 146 (2008), pp. 26-43. 
Modugno, M., and Kleopatra, N., 2009, "The Forecasting Power of International Yield Curve Linkages,” ECB WP No. 1044, April 2009.

Rudebusch, G., and Swanson, E., 2008, "Examining the Bond Premium Puzzle with a DSGE Model," Journal of Monetary Economics, Elsevier, Vol. 55 (Supplement), pp. S111S126, October.

Sims, C., 1980, “Macroeconomics and Reality,” Econometrica, 48 (1), 1-48.

Spencer, P., and Liu, Z., 2010, “An Open-Economy Macro-Finance Model of International Interdependence: The OECD, US and the UK," Journal of Banking and Finance, Elsevier, Vol. 34(3), pp. 667-680, March.

Stock, J., and Watson, M., 2005, "Understanding Changes in International Business Cycle Dynamics," Journal of European Economic Association, Vol. 3(5), pp. 968-1006. , and Watson, M., 2002, "Forecasting Using Principal Components from a Large Number of Predictors," Journal of the American Statistical Association, 97 (2002), pp. 1167-1179.

Wright J., 2011, "Term Premia and Inflation Uncertainty: Empirical Evidence from an International Panel Dataset," American Economic Review, 101(4): 1514-34. 